\title{
Arthroscopic assisted treatment of distal radius fractures and concomitant injuries
}

\author{
Tobias Kastenberger $^{1} \cdot$ Peter Kaiser $^{1} \cdot$ Gernot Schmidle $^{1} \cdot$ Peter Schwendinger $^{2} \cdot$ Markus Gabl $^{1} \cdot$ Rohit Arora $^{1}(\mathbb{C}$
}

Received: 3 February 2020 / Published online: 19 March 2020

(c) The Author(s) 2020

\begin{abstract}
Wrist arthroscopy is mainly used to assist fracture reduction and fixation and to diagnose and treat concomitant injuries mainly to the scapholunate (SL), lunotriquetral (LT) ligament and the triangular fibrocartilage complex (TFCC). Arthroscopy is beneficial in improving anatomical reduction of fracture steps and gaps in intra-articular distal radius fractures (DRFs). Yet, the literature that the functional outcome correlates with the use of arthroscopy, is limited. Non-surgical treatment and immobilization is recommended for Geissler grade I-III Sl-ligament injuries, while open reduction, ligament suture and/ or K-wire pinning is mandatory for complete ligament tears according to Geissler grade IV. This manuscript describes the current literature and gives insight into the authors' opinions and practice.
\end{abstract}

Keywords Distal radius fracture $\cdot$ Arthroscopic treatment $\cdot$ Concomitant injuries $\cdot$ Intrinsic ligament $\cdot$ Injury

\section{Introduction}

Distal radius fractures (DRFs) belong to the most common fracture type in humans. Depending on fracture fragment dislocation, fracture instability criteria, the patient's needs, and functional demands, treatment can vary between non-surgical treatment with cast immobilization and surgical treatment with open reduction and internal fixation.

Rohit Arora

rohit.arora@i-med.ac.at

Tobias Kastenberger

tobias.kastenberger@tirol-kliniken.at

Peter Kaiser

peter.kaiser@tirol-kliniken.at

Gernot Schmidle

gernot.schmidle@tirol-kliniken.at

Peter Schwendinger

Peter.Schwendinger@1khf.at

Markus Gabl

markus.gabl@tirol-kliniken.at

1 Department of Trauma Surgery, Medical University of Innsbruck, Anichstrasse 35, 6020 Innsbruck, Austria

2 Department for Trauma Surgery and Sports Traumatology, Academic Hospital Feldkirch, Carinagasse 47, 6800 Feldkirch, Austria
Nowadays, plating is the most common surgical treatment method for DRFs [1]. Wrist arthroscopy in DRFs underwent a cumulative evaluation in the last few decades [2-5]. Over the years, several authors have investigated the benefit of arthroscopy in the treatment of acute DRFs. Indications for arthroscopy in DRFs are multifragmented intra-articular fractures with comminution and/or die-punch fragments, associated carpal bone fractures or obvious intrinsic ligament injuries, an obvious widening of the distal radioulnar joint (DRUJ) suspecting a triangular fibrocartilage complex (TFCC) lesion, and radial styloid fractures because of a potential incomplete greater arch lesion with a SL ligament tear. Wrist arthroscopy is used for diagnostic and therapeutic purposes [6-11].

The following manuscript discusses the current literature regarding these indications and gives insight into the authors`opinions and practice.

\section{Epidemiology}

DRFs are still the most frequent fractures of the upper extremities of patients over 65 years old [12].

Incidence varies topographically. In Scandinavia, the incidence is 30 cases per 10,000 inhabitants per year [13]. Two peaks of prevalence are known: In younger years, at age ten (high energy trauma) and a peak incidence in young patients 


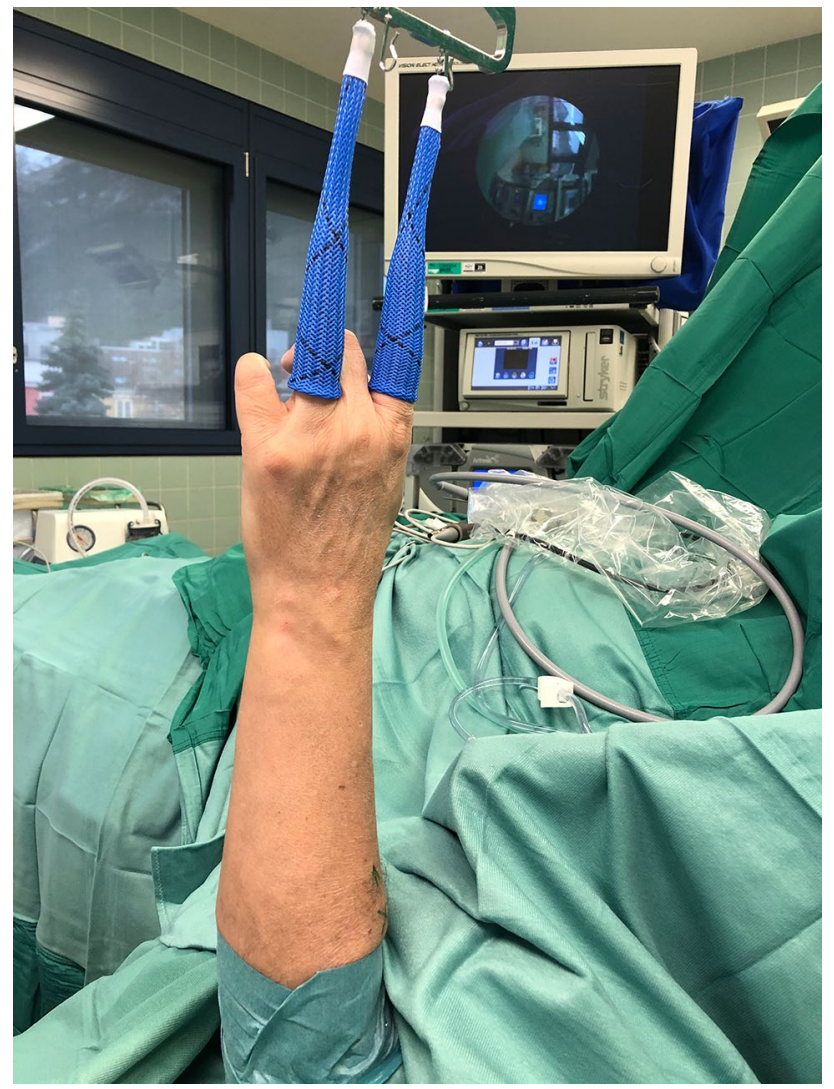

Fig. 1 Patient lying in a supine position with the upper extremity suspended by the use of finger traps

with a high functional demand [14], and in the elderly at the age of 60 (low energy trauma: fall from standing position). $70 \%$ of the fractures occur in women between the ages of 61 and 69 years [15].

\section{Clinical history}

DRFs had been a domain of conservative treatment formerly. During the last few decades, a paradigm shift occurred, from conservative therapy to surgical intervention and follow-up treatment with external fixators and $\mathrm{K}$-wires to volar angular stable plating [13]. Additionally, the use of volar locking plates increased from $42 \%$ of plated fractures in 1999 to $81 \%$ in 2007 [1].

Why these changes took place cannot be explained, and there is still no evidence for the increase in surgical intervention, especially for angular stable plating systems.

Concerning the changes in our society, fractures are advancing in complexity and patients are increasingly demanding from a functional perspective [5].

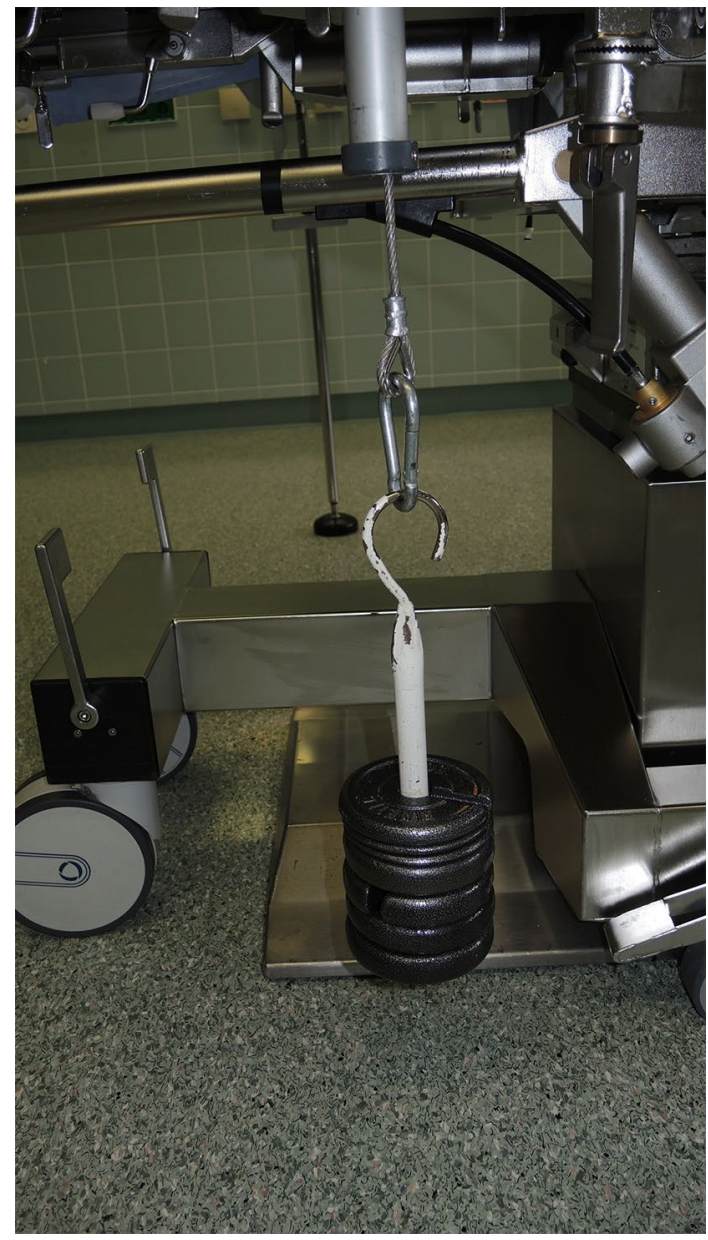

Fig. 2 Four kg traction weight applied on the wrist

\section{Indications}

A main indication for arthroscopy in DRFs is an intra-articular step or gap from 1 to $2 \mathrm{~mm}$ after closed reduction [5], which is a prognostic factor for post traumatic osteoarthritis $[16,17]$. Arthroscopically assisted treatment of DRFs can help detecting and treating scaphoid fractures and/or ligament injuries. Radiographic findings may hint to soft tissue injuries e.g., inter-carpal joint space widening or disruption of the Gilula lines.

Radial styloid fractures (chauffeurs fracture) without the dislocation of the lunate may be part of greater arch injuries described by Mayfield [18].

Widening of the DRUJ may hide an injury of the TFCC, which can be verified arthroscopically.

Complex multifragmented intra-articular fractures such as three-part/four-part fractures associated with intra-articular comminution (explosion type fractures) may need arthroscopic evaluation, reduction, and fixation, and in die-punch fractures, arthroscopy is suggested too [10]. Few authors 


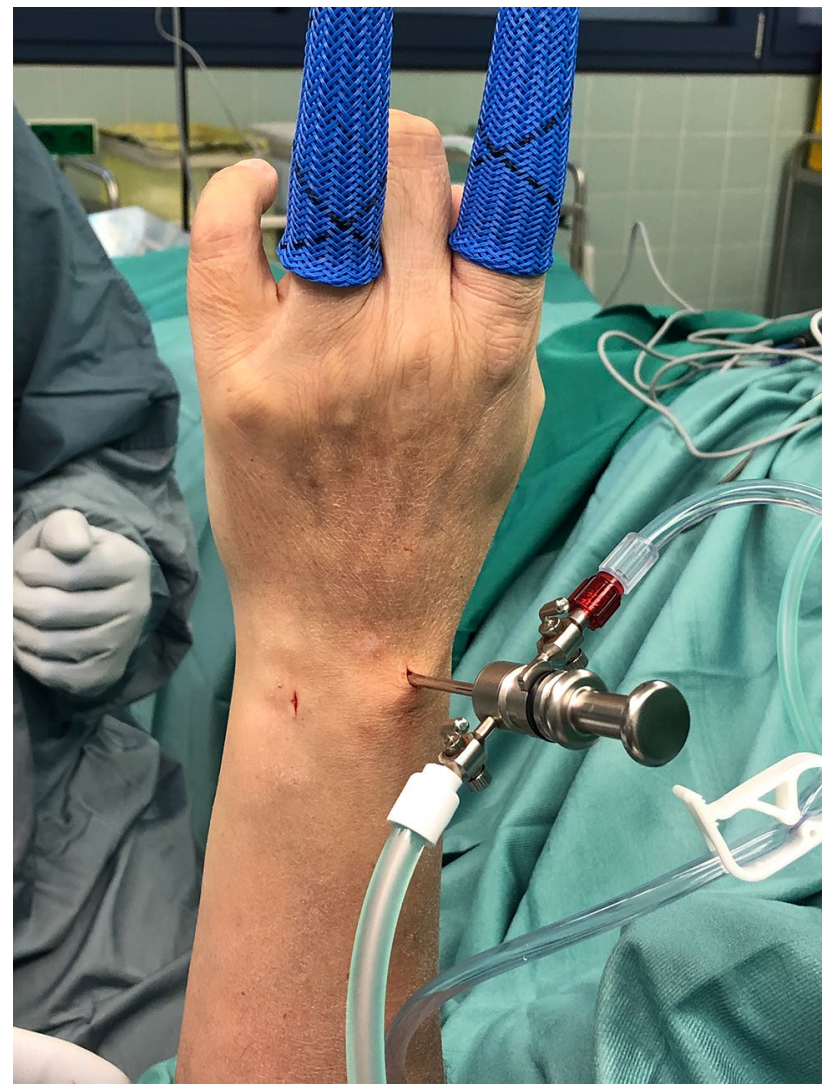

Fig. 3 Standard arthroscopy portals $3 / 4$, and $6 \mathrm{R}$ with the camera in the $3 / 4$ portal

even recommend wrist arthroscopy for any kind of DRF [19].

The authors perform arthroscopy in the following cases:

- Intra-articular DRFs with a sagittal fracture line mainly at the height of the scapholunate ligament to evaluate any concomitant scapholunate ligament injury.

- Intra-articular DRF with a sagittal or frontal fracture line with larger relevant fragments for fracture reduction to minimize fracture steps and gaps (e.g., Die punch fragments).

- Intra-articular DRFs with an impacted central fragment to evaluate correct fragment reduction.

- Intra-articular DRFs with an unstable, DRUJ for TFCC assessment [20].

- Galeazzi type DRFs with a loss of radial length of $>6 \mathrm{~mm}$.

- DRFs with radiologic predictors of DRUJ instability (radial inclination $<11^{\circ}$, dorsal tilt $>20^{\circ}$, radioulnar interval $>2 \mathrm{~mm}$, base fractures of the ulnar styloid process).
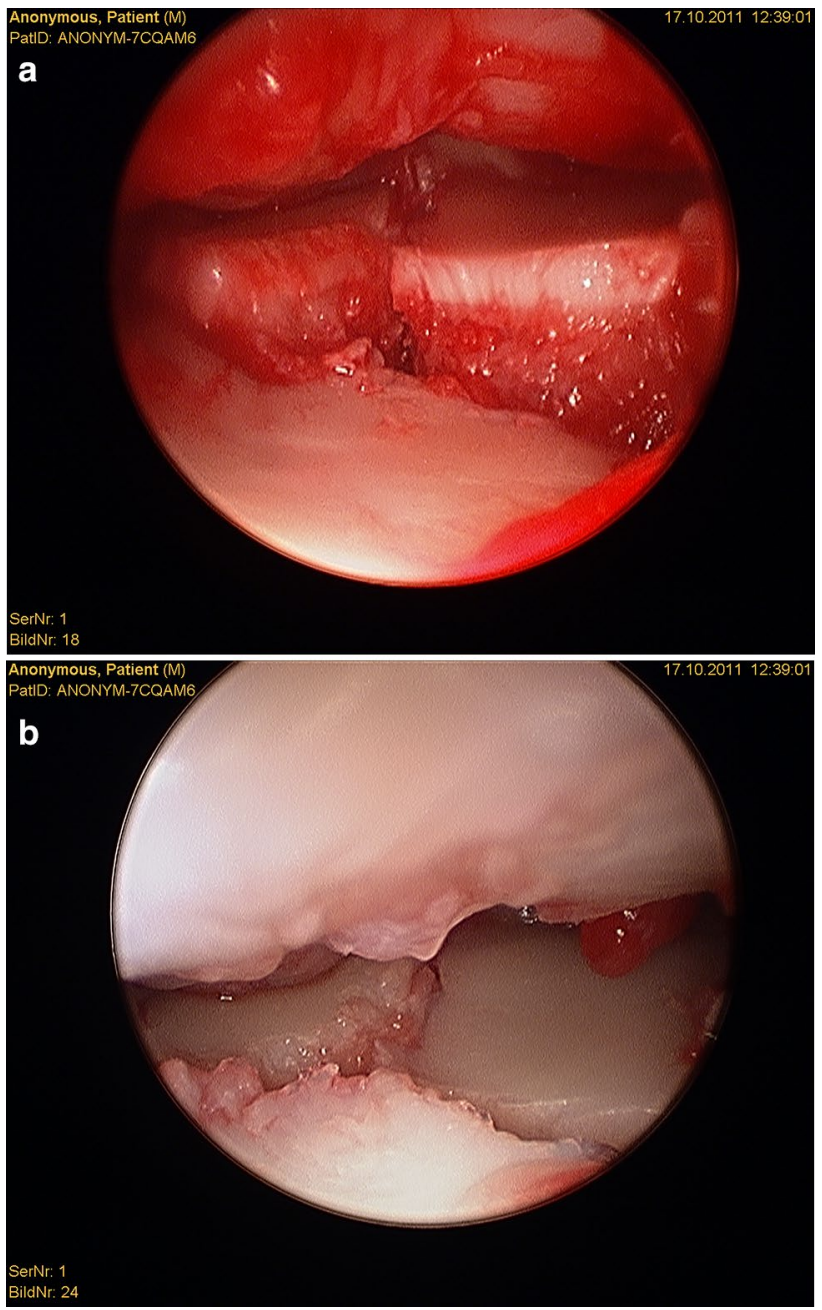

Fig. 4 Radiocarpal view $\mathbf{a}$ before fracture reduction and $\mathbf{b}$ after fracture reduction

- DRFs with scapholunate interval opening during dynamic intraoperative fluoroscopic evaluation with radial- and ulnar abduction.

\section{Contraindications}

Low-activity patients, extra-articular fractures in the elderly, open fractures, and DRFs associated with other multiple fractures are reported to be contraindications for wrist arthroscopy [19].

\section{Wrist arthroscopy setup}

Although simple diagnostic wrist arthroscopy and soft tissue procedures can be performed under wide awake local anesthesia and no tourniquet (WALANT) surgery [21], patients with intra-articular DRFs are usually treated under general 
or regional anesthesia, in case of the need for manipulation of fracture fragments, which might be painful [19].

The patients are in supine position with the fingers hanging by the use of extension sleeves (Fig. 1).

Traction is applied by dead weights (approximately 3-4 kg) (Fig. 2).

An Esmarch tourniquet on the arm is inflated for exsanguination to 200-250 $\mathrm{mm} \mathrm{Hg} \mathrm{[19].}$

The authors usually use "dry" arthroscopy according to the recommendations of Del Pinal [22] to prevent extravasation, to minimize soft tissue swelling and secondary compartment syndrome [19, 22]. In "dry" wrist arthroscopy, the air valve is kept open to enable free air circulation through the joint and suction should be switched off unless needed. One disadvantage is the potential loss of vision due to splashes on the tip of the scope, or blood and debris in the joint. If required, the joint can be irrigated using saline to remove debris and blood to increase visibility. The surgeon should switch to "wet" arthroscopy when using thermal probes because heat generation may damage the cartilage [22]. If needed, a pump pressure of $15 \mathrm{mmHg}$ should be sufficient [5].

The authors use a $2.7 \mathrm{~mm}$ probe with a $30^{\circ}$ field of view angle. The radiocarpal joint is typically assessed using the $3 / 4,5 / 6$ and $6 \mathrm{R}$ portal, and the midcarpal joint using the midcarpal radial and ulnar portals (Fig. 3).

Any fracture steps or gaps, chondral lesions, and the TFCC itself are assessed via the radiocarpal portals, whereas the SL and LT ligaments are assessed via the midcarpal portals.

Before using arthroscopy as a standardized procedure, experience is required, to prevent prolongation of surgical time, as well as an increase in iatrogenic injury risks (nerve and tendon lacerations). Arthroscopy shows an exponential

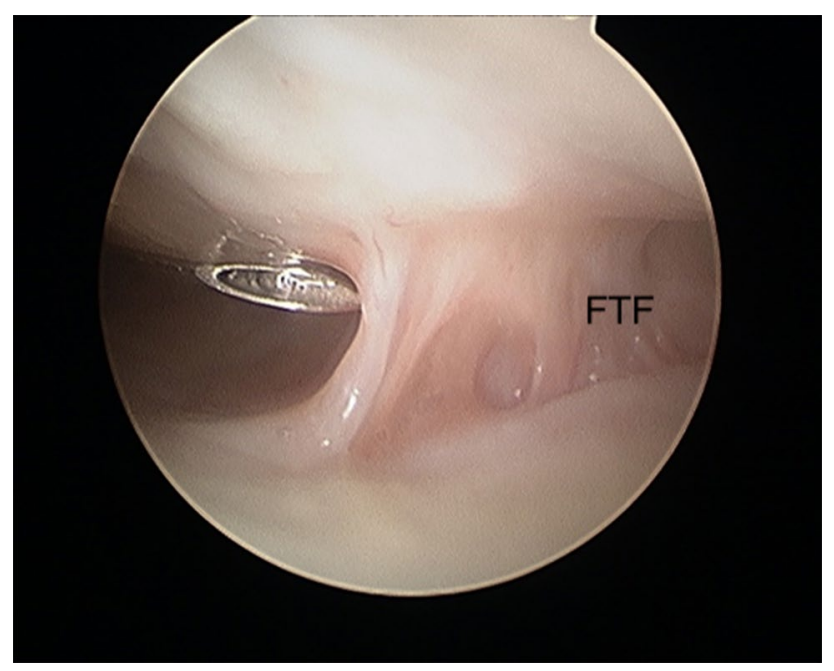

Fig. 5 Intra-articular fibrous tissue formation (FTF)

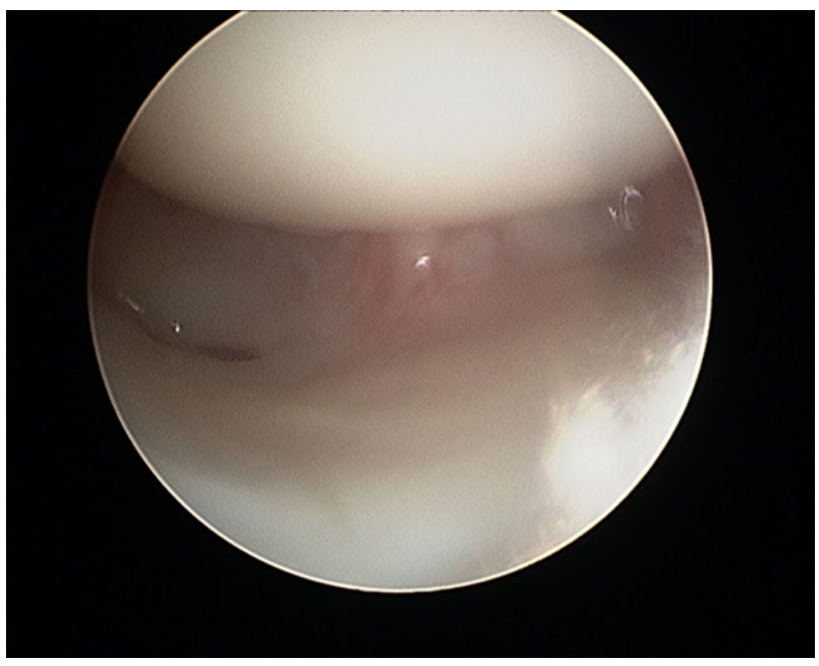

Fig. 6 Intra-articular view after debridement of FTF

learning curve with a reduction of complication rates by time with ongoing surgeon experience, and a threshold at over 5-year expertise [5, 23].

\section{Assisted fracture reduction}

Intra-articular DRFs should be reduced anatomically without any persisting steps, as the latter correlates with radiocarpal osteoarthritis and an unsatisfactory result [16]. Recent findings indicate a critical tolerance for joint incongruity in the distal radius may be as little as $1 \mathrm{~mm}$ [24-27].

Therefore, it seems reasonable to invest all effort into adequate intra-articular fracture reduction. Arthroscopy is used to directly visualize any intra-articular gaps and stepoffs and fracture reduction under visualization.

Reports with good illustrations showing the technique of arthroscopic fracture reduction are published by Del Pinal et al. [28], Ardouin et al. [5], and Lutz et al. [29]. Arthroscopy can be performed either before or after initial fracture reduction [30]. We initially performed an extra-articular fracture reduction of the metaphysis and fixation of the reduced fragments using a plate that is fixed at the radius shaft. Ligamentotaxis and indirect manipulation of intraarticular fracture fragments using the "joysticks reduction technique of the joint surface" is performed under fluoroscopic control. Intra-articular fracture fragments are temporarily stabilized using K-wires [31].

The plate is fixed through its gliding hole in the diaphysis to ensure a more distal or proximal plate position. Additional $\mathrm{K}$-wires can be inserted distally to stabilize the reduced intra-articular fragments [32].

After plate presetting, the forearm is placed in a vertical traction tower and extension weight is applied. One longitudinal incision is placed at the $3 / 4$ portal between the extensor 


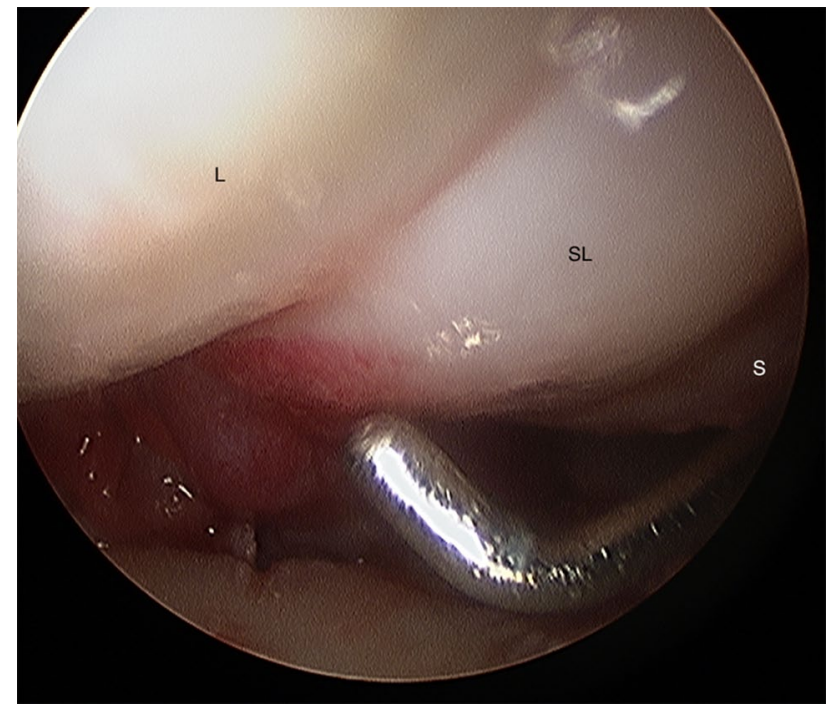

Fig. 7 Radiocarpal view: balloon sized scapholunate ligament Geissler grade 1; $L$ lunate, $S L$ scapholunate ligament, $S$ scaphoid

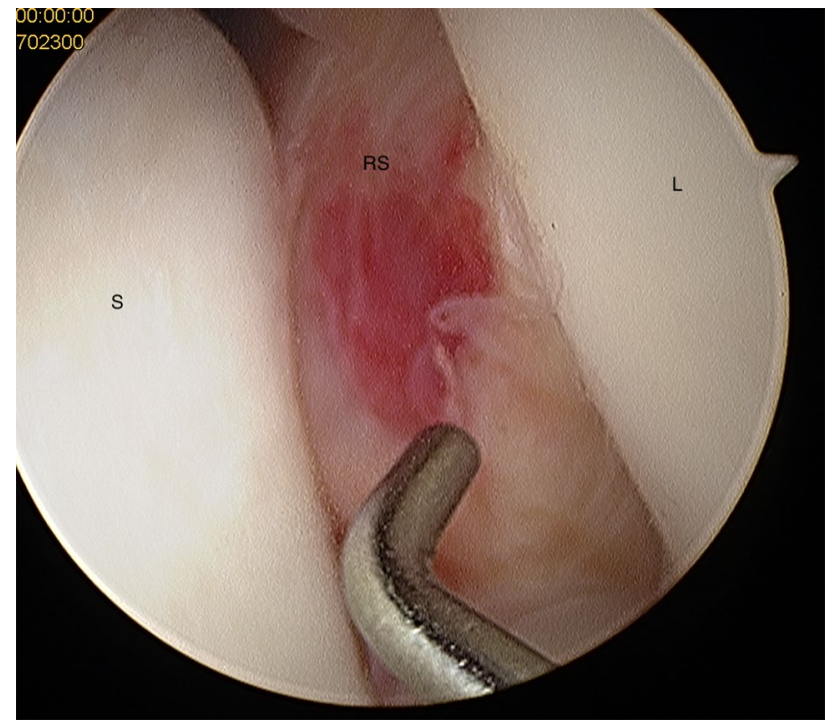

Fig. 8 Midcarpal view: radius joint surface can be seen with the hook between scaphoid and lunate indicating a scapholunate ligament tear Geissler grade 4; $S$ scaphoid, $R S$ radial joint surface, $L$ lunate pollicis longus tendon and the extensor digitorum communis tendon. A $2.7 \mathrm{~mm}$ arthroscope is inserted to inspect the joint. A second longitudinal incision is placed at the $6 \mathrm{R}$ portal and a probe is inserted which can be used to manipulate the intra-articular fragments (Fig. 4a, b). The remaining hematoma should be removed for better visualization.

In cases of increased steps or gaps, the K-wires are driven back and an improvement of intra-articular reduction is performed under direct arthroscopic visualization. As long as the fracture is only temporary reduced and fixed using $\mathrm{K}$-wires, every step and gap can be addressed by removing a particular K-wire to loosen that specific fragment. The reduction of this fragment is conducted under direct visualization using a hook probe. The loosened K-wire is introduced through the fracture fragment for temporary fixation. Additionally, traction through the finger traps helps to ensure radial inclination.

The joint surface and the intrinsic ligamentous injuries are inspected from the 3-4 portal arthroscopically. Debridement of joint cartilage fragments, fracture hematoma, and early granulation tissue can be performed using a shaver [19].

Once the reduction has been completed successfully, the epiphyseal screws are positioned through the plate drill holes, and the K-wires are removed. One last joint inspection after distal screw positioning is performed checking the absence of intra-articular screw protrusion and intraarticular fragment stability.

Finally, a fluoroscopy is used to check the screw length in an anterior- posterior, lateral, and dorsal-horizontal view.

Several studies have been conducted to address the question whether fluoroscopically or arthroscopically assisted reduction leads to a better articular surface restoration regarding the size of steps and gaps. A systematic review including 720 patients with a follow-up of 0-38 months (16 studies; level of evidence II-IV) showed that most studies $(13 / 16)$ were in favor of arthroscopy, improving articular reduction [33].

However, most studies had a small sample size, short follow-up and/or used a case-series design, which is unable to answer the question of articular reconstruction [33].

Table 1 Geissler classification [40]

\begin{tabular}{ll}
\hline Grade & Description \\
\hline Geissler I & $\begin{array}{l}\text { Hemorrhage of the interosseous SL ligament seen from the radiocarpal joint. No incongruence of carpal alignment in the midcarpal } \\
\text { space }\end{array}$ \\
Geissler II & $\begin{array}{r}\text { Hemorrhage of interosseous SL ligament seen from the radiocarpal joint. Incongruence/step-off seen from the midcarpal space. A } \\
\text { slight gap (less than the width of a probe) between carpals may be present }\end{array}$ \\
Geissler III $\begin{array}{r}\text { Incongruence/step-off of carpal alignment seen in both the radiocarpal and midcarpal spaces. The probe may be passed through the } \\
\text { gap between carpals }\end{array}$ & $\begin{array}{r}\text { Incongruence/step-off of carpal alignment seen in both the radiocarpal and midcarpal spaces. Gross instability with manipulation. } \\
\text { A 2.7-mm arthroscope may be passed through the gap between carpals from the midcarpal space }\end{array}$
\end{tabular}


Table 2 Arthroscopic EWAS (European Wrist Arthroscopy Society) Classification
Arthroscopic stage Arthroscopic testing of SLIOL from MC joint (EWAS)

\begin{tabular}{ll}
\hline I & No passage of the probe in SL space but synovitis \\
II & Lesion of membranous SLIOL \\
& Passage of the tip of the probe in the SL space without widening (stable) \\
III A & Partial lesion involving the volar SLIOL \\
& Volar widening on dynamic testing from MC joint (anterior laxity) \\
III B & Partial lesion involving the dorsal SLIOL \\
& Dorsal SL widening on dynamic testing (posterior laxity) \\
III C & Complete SLIOL tear, joint is reducible \\
& Complete widening of SL space on dynamic testing, reducible with removal of probes \\
IV & Complete SLIOL with SL gap \\
& SL gap with passage of the arthroscope from MC to RC joint \\
No radiographic abnormalities & Wide SL gap with passage of the arthroscope through SL joint \\
& Frequent X-ray abnormalities such as an increased SL gap, DISI deformity
\end{tabular}

SLIOL scapholunate interosseous ligament, $M C$ midcarpal, $R C$ radiocarpal, $R S C$ radio-scapho-capitate, $L R L$ long radiolunate, DIC dorsal intercarpal ligament, $S L$ scapholunate, $T H$ triquetro-hamate, $S T$ scaphotrapezial, $D R C$ dorsal radiocarpal, DISI dorsal intercalated segmental instability

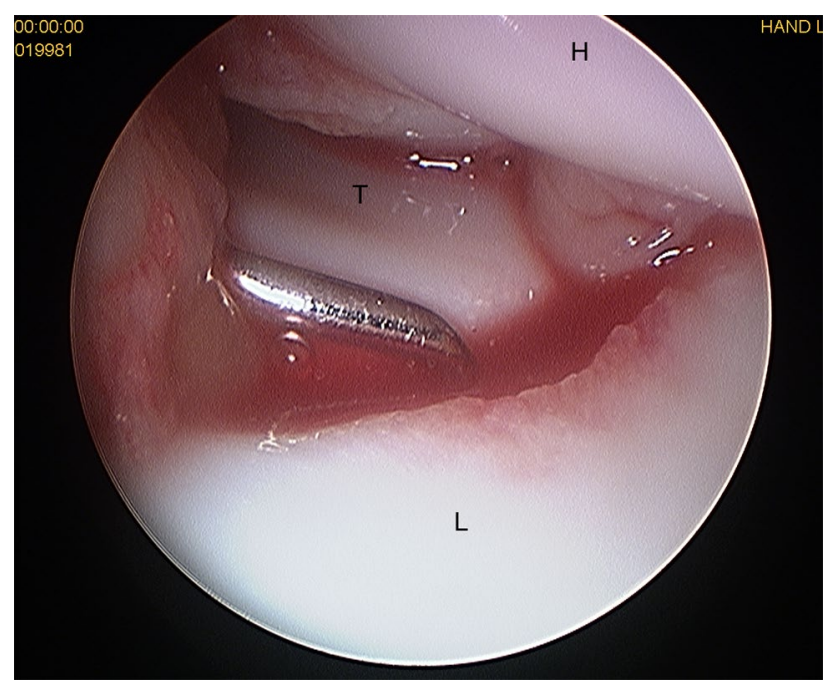

Fig. 9 Midcarpal view: widening of the lunotriquetral joint with the hook between the triquetrum and lunate indicating a lunotriquetral ligament tear; $T$ triquetrum, $L$ lunate, $H$ hamate

Furthermore, the correlation of anatomical reconstruction with the clinical and functional outcome, that has more importance for the treated patients, could not be answered in any of the studies.

Catalano et al. and Goldfarb reported that short and longterm functional outcomes did not correlate with the magnitude of the residual step-off and gap displacement, with the awareness that most of the patients had a good restoration of extra-articular alignment with surgical treatment and few had major articular incongruities [27, 34-36].

Regarding the question whether arthroscopy helps to improve functional scores at last follow-up, Saab et al. reported that only $50 \%$ of the studies (6/12 studies; level of evidence II-IV) were in favor of arthroscopy. However yet again, most studies had a small sample size, short follow-up and/or used a case-series design [33].

Arthroscopy allows us to visualize acute chondral lesions of the distal radial joint surface which can be seen as subchondral hematomas, cracks, avulsed cartilage flakes, or complete avulsions of the cartilage [10]. Subchondral hematoma may lead to osteoarthritis as well as destroyed cartilage [37]. Currently, debridement appears to be the only available option, although micro fracturing may be attempted without adequate proof of its benefit [10]. Yet, severely comminuted radius fractures with destroyed cartilage may even need, or benefit from, partial wrist fusion or hemi-arthroplasty instead of arthroscopically assisted open reduction and internal fixation [10, 36, 38-41].

Gabl et al. [42] investigated the formation of post-operative intra-articular fibrous tissue in DRFs which potentially causes loss of radio-carpal motion (Figs. 5 and 6). The author found that fibrotic tissue develops and extends from former fracture gaps to the SL ligament and the dorsal joint capsule, while undamaged cartilage remains without fibrous tissue formation. All fibrous tissue was too tight to be removed without shaving and potentially limited the range of motion of the proximal carpal row [42]. Therefore, arthroscopic debridement after fracture healing at the time of implant removal of these intra-articular fibrous scar tissues may improve the range of motion and functional scores.

Finally, it seems that arthroscopic removal of intra-articular hematoma and debris during primary surgical fracture fixation did not show any benefits regarding functional outcome in comparison to patients treated via open reduction and internal fixation alone [43]. 


\section{Concomitant soft tissue injuries}

The authors adapt to the circumstances of the surgery regarding the order of investigation of further concomitant injuries, which are mainly TFCC, SL and LT ligament injuries. They are assessed either before or after definite fracture reduction and fixation.

Concomitant injuries to the SL ligament occurs in about $30-50 \%$ [5, 44-46]. A systematic review described a lesion of the scapholunate interosseous ligament in $41 \%$ (12 studies; 467 patients; mean follow-up 22 months). $76.2 \%$ were classified as Geissler grade I or II and $23.8 \%$ as Geissler grade III or IV.

LT injuries are reported in 8.5-15\% [44, 47] and TFCC injuries in more than $50 \%$ with the majority showing degenerative origin $[5,10,46]$.

\section{SL and LT ligament injuries}

It is important to evaluate SL and LT ligament injuries associated with DRFs, as these can be part of incomplete greater arch injuries as described by Mayfield et al. [18]. These injuries can be directly visualized and classified as partial or complete along their dorsal, membranous, and palmar parts [10] (Figs. 7 and 8). The degree of injuries can be classified according to Geissler [48] (Table 1) or the latest EWAS (European Wrist Arthroscopy Society) classification (Table 2). The latter EWAS classification will be used in future scientific evaluations, however, because most of the cited studies used the Geissler classification, the current manuscript also reports the treatment suggestions according to the Geissler classification. The widening of inter-carpal joint spaces reflect the degree of mobility/instability of the affected joint as a consequence of ligamentous injury.

These injuries have the potential to proceed to SL dissociations and secondary carpal instability if left untreated [7], and eventually lead to posttraumatic scapho-lunate advanced collapse (SLAC) osteoarthritis [10]. It is important to detect and properly treat tears early to avoid long-term problems.

Geissler suggested immobilization of grade I injuries, arthroscopic reduction, and K-wire pinning for grade II injuries, arthroscopic or open reduction and K-wire pinning for grade III injuries, and open reduction and repair for grade IV injuries [48].

This approach seems too aggressive because patients with low grade incomplete tears (grade I and II) are asymptomatic at 1 year after DRF surgery [7] if only immobilized. There were no long-term findings for developing a SLAC wrist for grade I and II [49]. The immobilization protocol after palmar plating needs to be adapted, depending on the grade of SL injury [50].

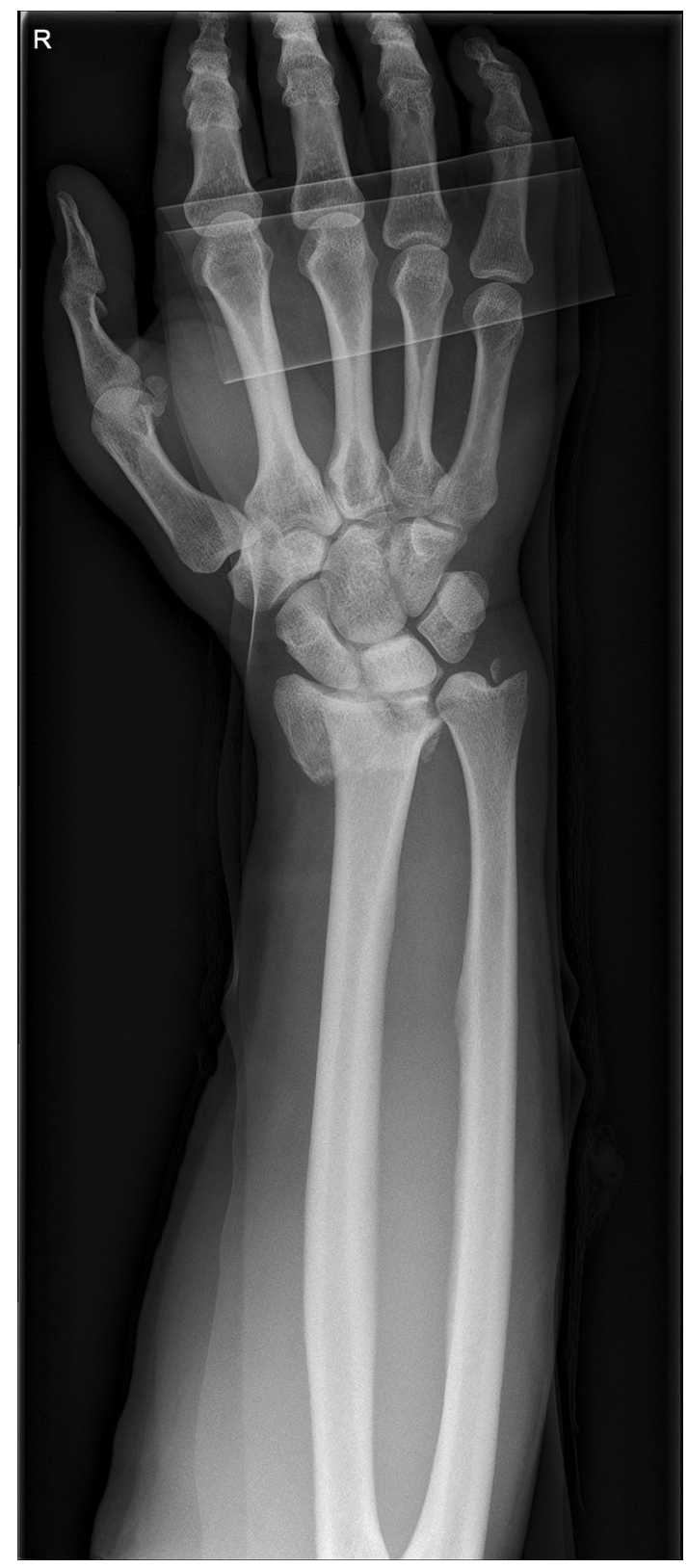

Fig. 10 Dorsovolar view: initial assessment of the injured wrist with a loss of the radial inclination and radial length

The treatment of grade III injuries remains controversial. Several authors besides Geissler advocate K-wire pinning [33, 51-55]. However, there were no differences found in the subjective, objective, or radiographic outcome after grade III and grade I/II untreated tears associated with displaced DRFs [49]. The reason for such findings may be the secondary stabilizers of the wrist.

Acute grade IV injuries show a dynamic instability and need surgical treatment using arthroscopic or open reduction and K-wire pinning and/or anchor fixation [10]. Typically, the scapho-lunate and the scapho-capitate joints are 


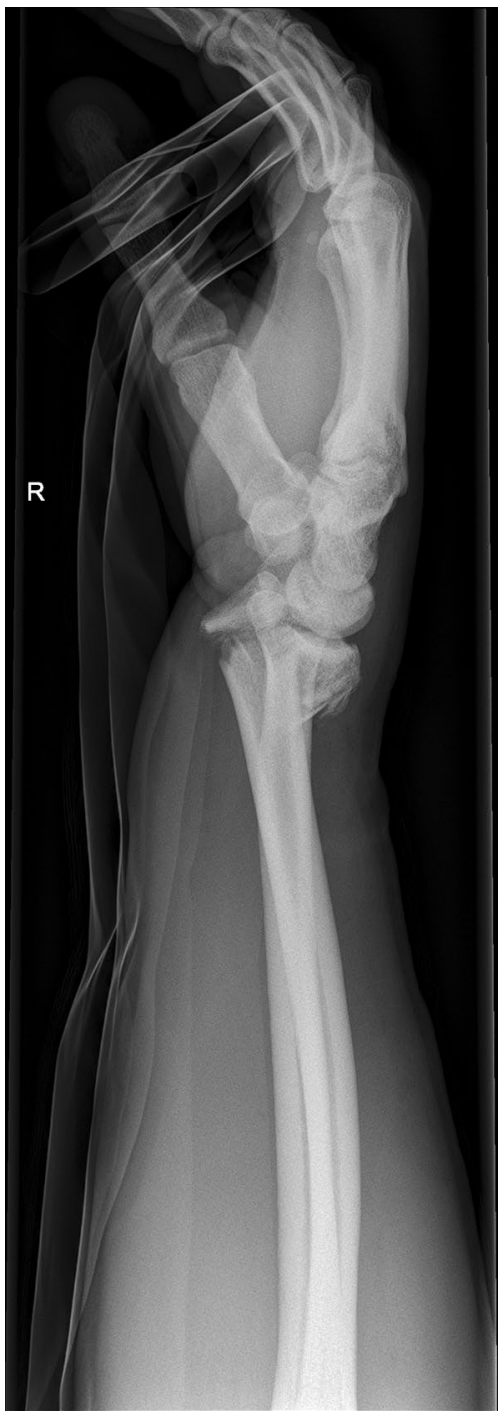

Fig. 11 Lateral view: initial assessment showing the loss of radioulnar and dorso-palmar inclination

transfixed using K-wires. Additional cast fixation is needed for 8-10 weeks until the $\mathrm{K}$-wires are removed.

A similar approach is recommended for LT injuries (Fig. 9) and is also used by the authors. Stable grade I, II, and III injuries are immobilized for up to 4 weeks depending on the stability of fracture fixation and bone quality, and grade IV injuries need arthroscopic debridement and percutaneous K-wire pinning with an immobilization for 8 weeks [10].

However, the evidence of this approach is limited. There are no long-term studies investigating the impact of cast fixation in partial injuries. Additionally, it is questionable if the improved diagnosis using arthroscopy, and the resulting treatment of lower graded injuries leads to a better functional outcome. Swart and Tang [55] did not find any major

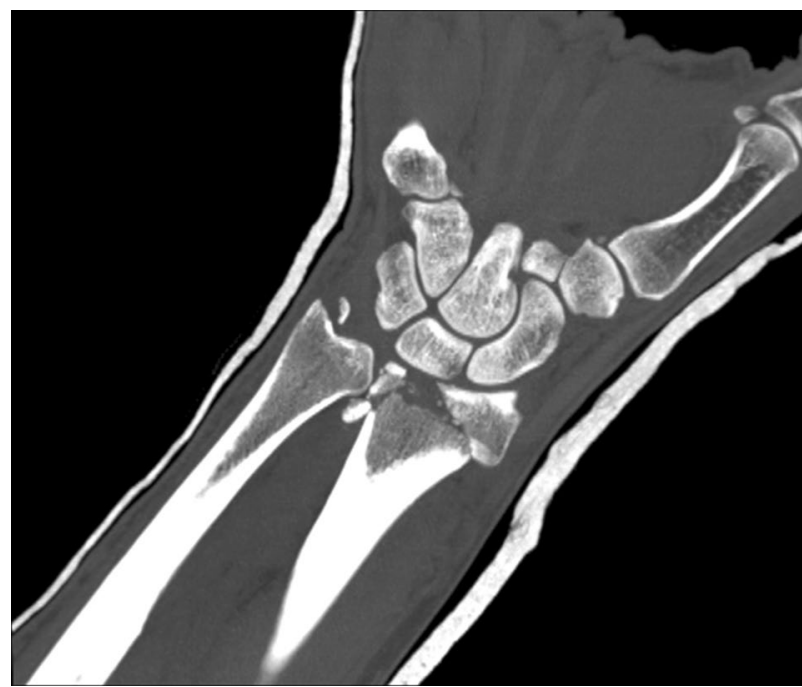

Fig. 12 CT scan of a dorsovolar view after reduction and cast immobilization showing the defect zone of the intermediated column and fracture involvement of the DRUJ

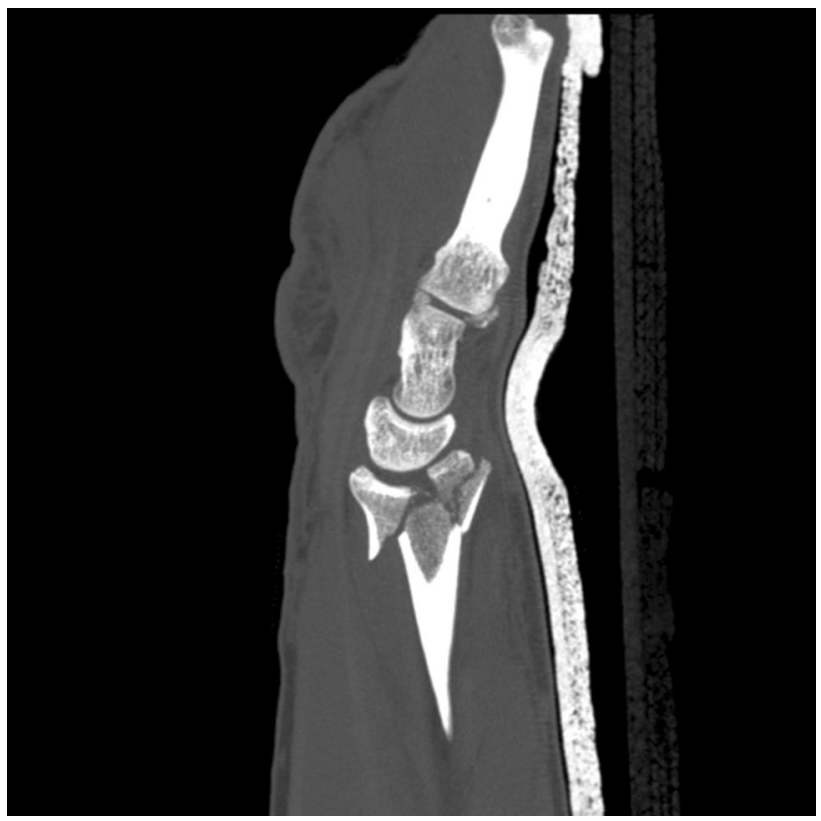

Fig. 13 CT scan of a lateral view of the intermediate column showing the volar fragment of the intermediate column, a fracture gap and step of more than $2 \mathrm{~mm}$ and the volar fragment additionally toppled

differences in the subjective and objective outcome measurement in patients with and without ligament injuries.

\section{TFCC injuries}

The importance of TFCC tears and DRUJ instability is explained in a separate chapter within this journal. 


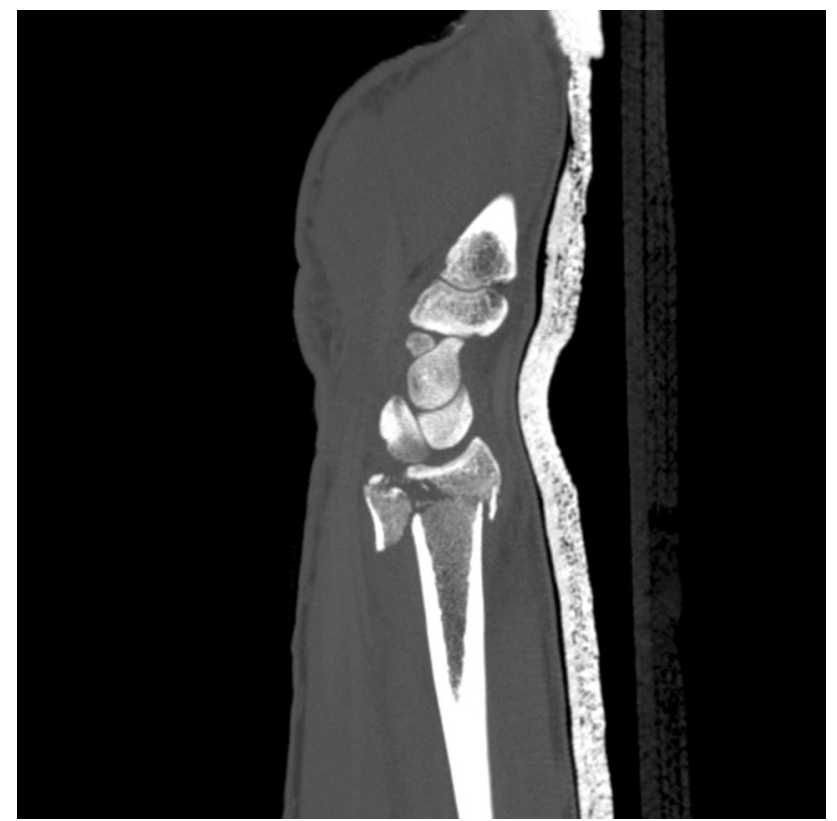

Fig. 14 CT scan of a lateral view of the ulnar column showing the additional ulnar fragment flipped $90^{\circ}$

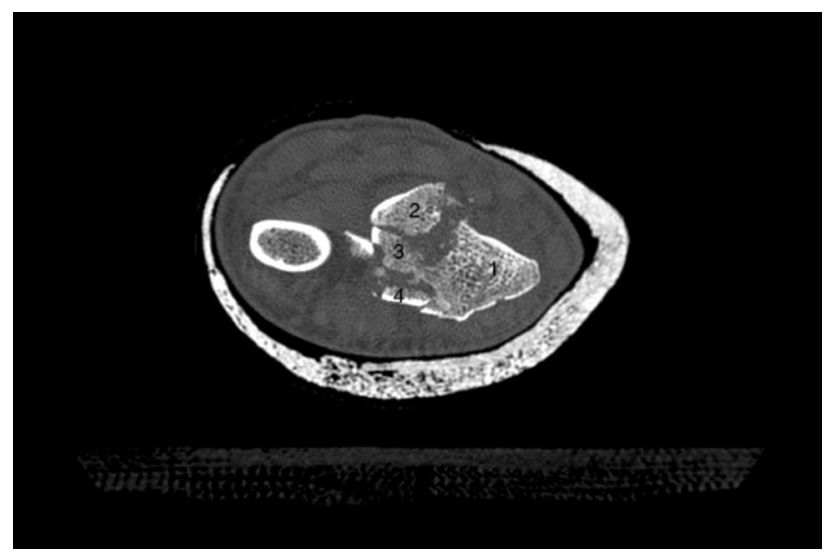

Fig. 15 CT scan of an axial view with the numbered intraarticular fragments 1: radial styloid, 2: dorso-ulnar fragment, 3: fragment of the intermediate column 4 : volar fragment

Therefore, the authors will not discuss any details in this manuscript [20].

\section{Complications}

At least the complication rate following wrist arthroscopy is low. The most reported complications of wrist arthroscopy are: procedure failure $1.16 \%$ and nerve injuries $1.17 \%$; tendon lacerations are less frequent [23].

Other complications include a loss of reduction, loosening of a K-wire, pin infections, complex regional pain

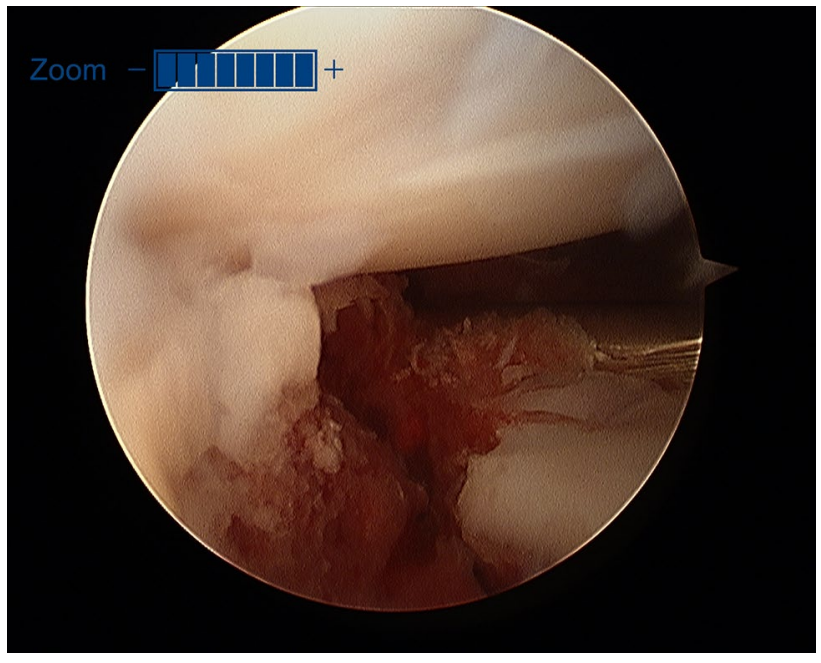

Fig. 16 Initial view of the displaced fracture fragments after inserting the arthroscope through the $3 / 4$ portal

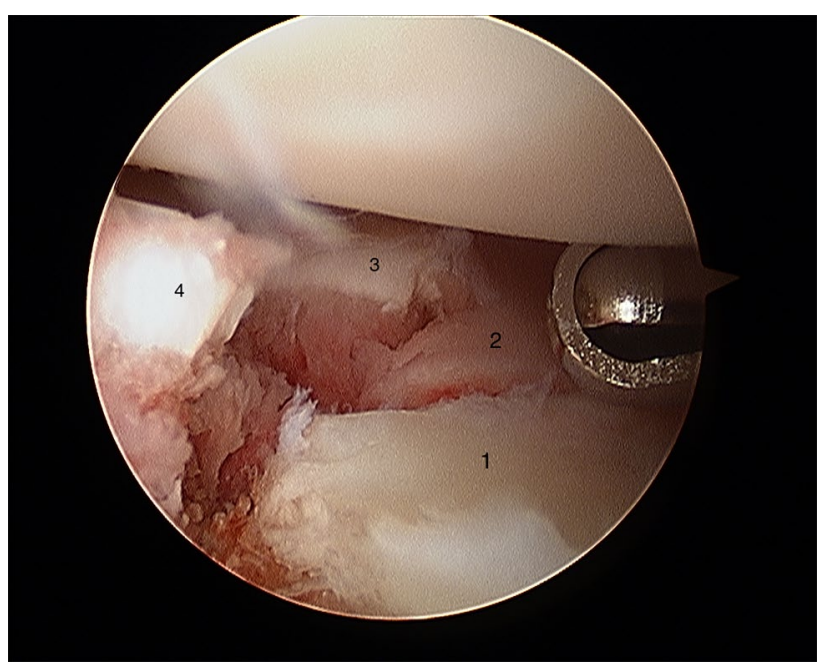

Fig. 17 Arthroscopic view after debridement using the wrist shaver; all fragments are visualized. 1: radial fragment, 2: volar fragment, 3: intermediate fragment, 4: dorsal fragment

syndrome, cartilage lesions, joint stiffness, and remaining loose bodies [23, 56, 57].

\section{Conclusion}

Wrist arthroscopy appears to be beneficial in diagnosing intra-articular steps and gaps, as well as concomitant injuries to the scapholunate and lunotriquetral ligament, and the triangular fibrocartilage complex in DRFs. It allows any step-off or gap malalignment to be addressed via direct visualization. The author`s indications for wrist arthroscopy in 


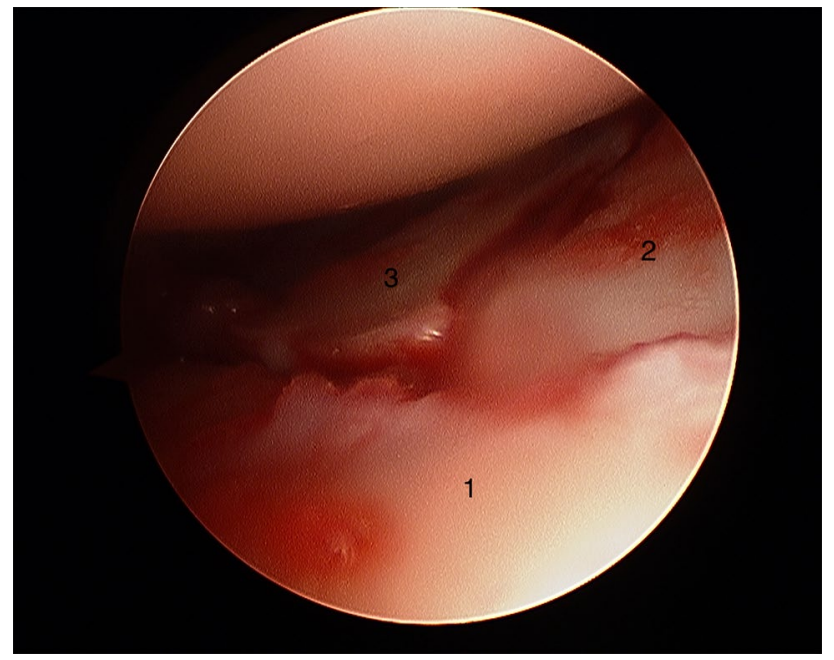

Fig. 18 Arthroscopic view after arthroscopical fracture reduction showing an anatomical alignment of the involved fragments. 1: radial fragment, 2: volar fragment, 3: intermediate fragment

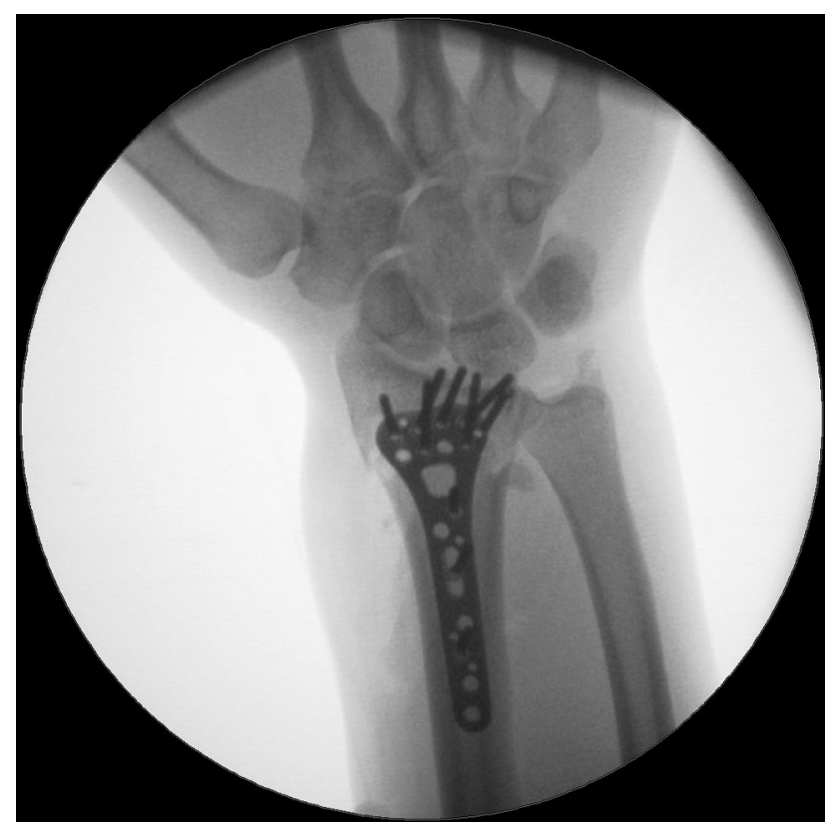

Fig. 19 Dorsovolar fluoroscopic view at the end of the surgery showing the main screw fixation directed to the ulnar corner

DRF's are intra-articular fractures with a sagittal fracture line at the level of the scapholunate ligament to exclude a scapholunate ligament injury, intra-articular DRF with a sagittal or frontal fracture line with larger relevant fragments for fracture reduction to minimize fracture steps and gaps (e.g., Die punch fragments), intra-articular DRF with an impacted central fragment to evaluate correct fragment reduction, intra-articular DRF with an unstable DRUJ for TFCC assessment and DRF with a scapholunate interval

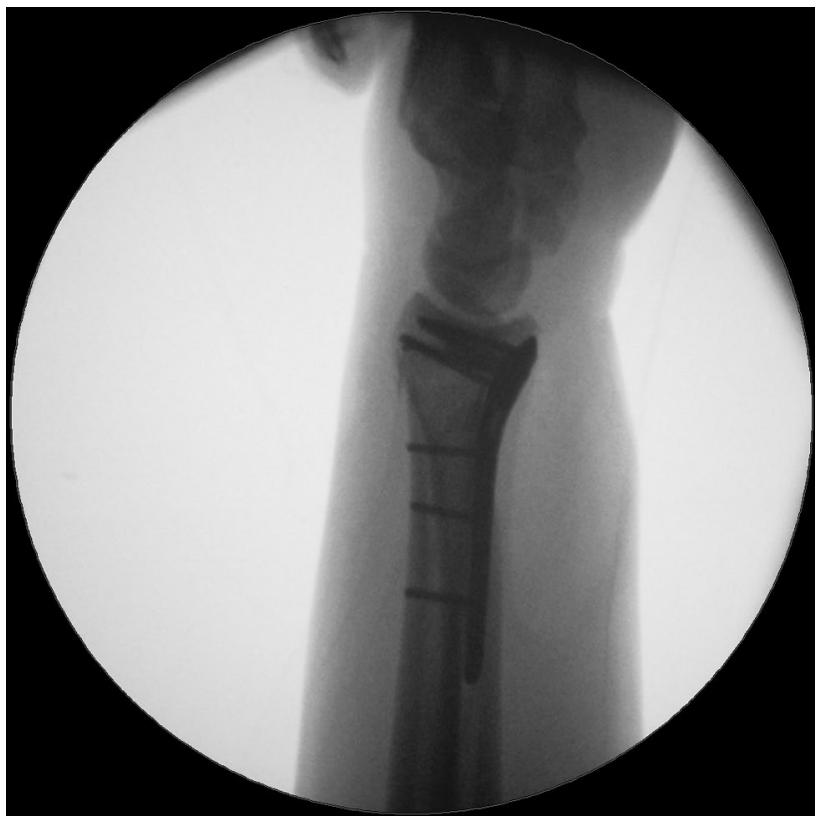

Fig. 20 Lateral fluoroscopic view showing the screws in a subchondral position

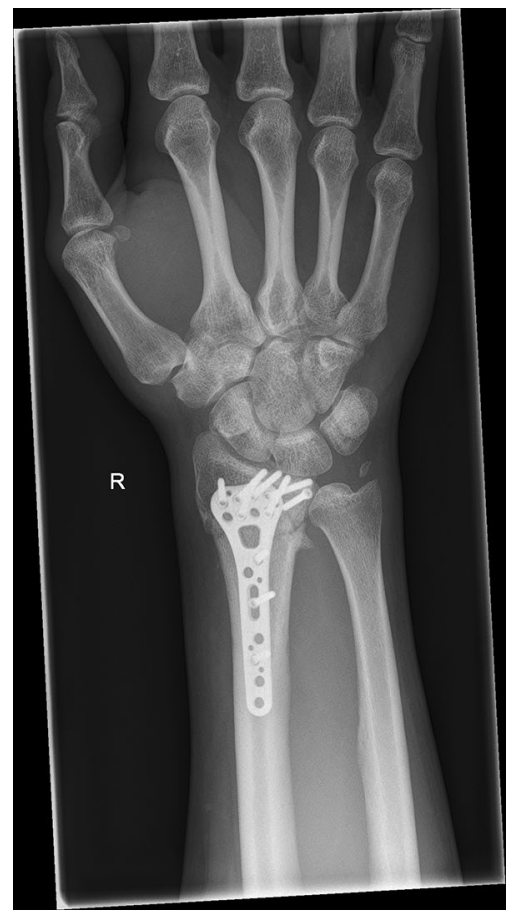

Fig. 21 Dorsovolar and lateral x-ray control four weeks after surgery

opening during dynamic intraoperative fluoroscopic evaluation with radial and ulnar abduction. For the authors, nonsurgical treatment and immobilization for up to 4 weeks is recommended for Geissler grade I-III SL and LT injuries because the effort of arthroscopically conducted ligament 


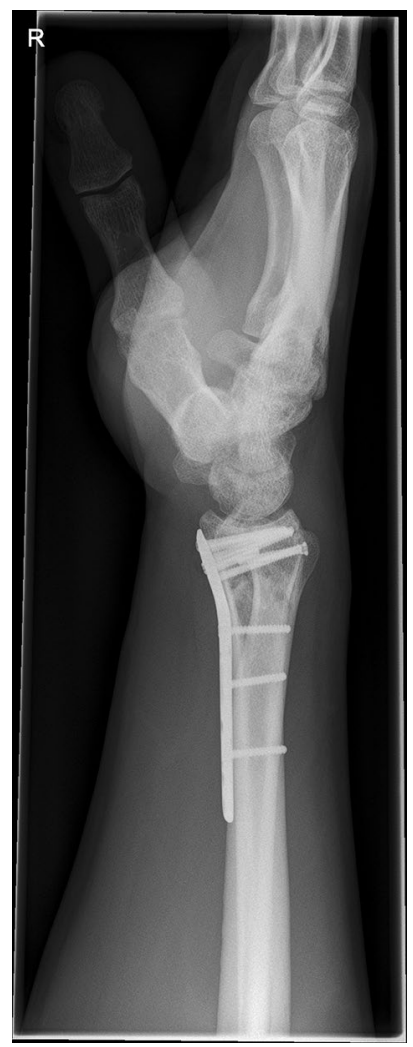

Fig. 22 Dorsovolar and lateral X-ray control 4 weeks after surgery

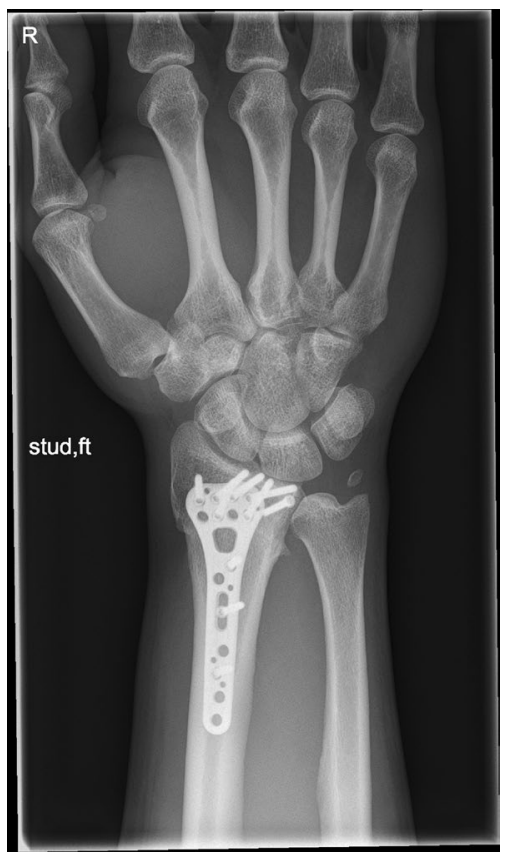

Fig. 23 Dorsovolar and lateral X-ray control 1 year after surgery

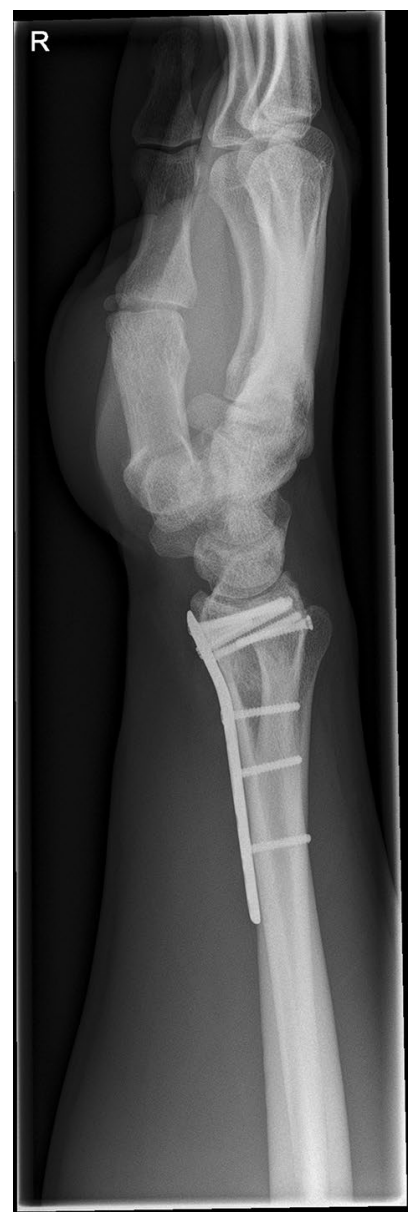

Fig. 24 Dorsovolar and lateral X-ray control 1 year after surgery

repair has to be regarded critically in these cases as patients' benefits have not been proven. Open reduction, ligament suture, and/or K-wire pinning is mandatory for complete ligament tears Geissler grade IV.

However, to date, there is limited evidence that arthroscopy shows benefits in clinical outcome parameters. Prospective long-term studies are needed to confirm the need and beneficial role of arthroscopy and the proposed treatment regime in DRFs as well as SL and LT injuries.

\section{Clinical case}

We present a case of a male patient aged 31 years who sustained an intra-articular four-part DRF in 2011. The main instability area is located at the intermediate column. The initial antero-posterior (Fig. 10) and lateral (Fig. 11) X-rays show a loss of the radial length, radio-ulnar and dorso-palmar inclination. 


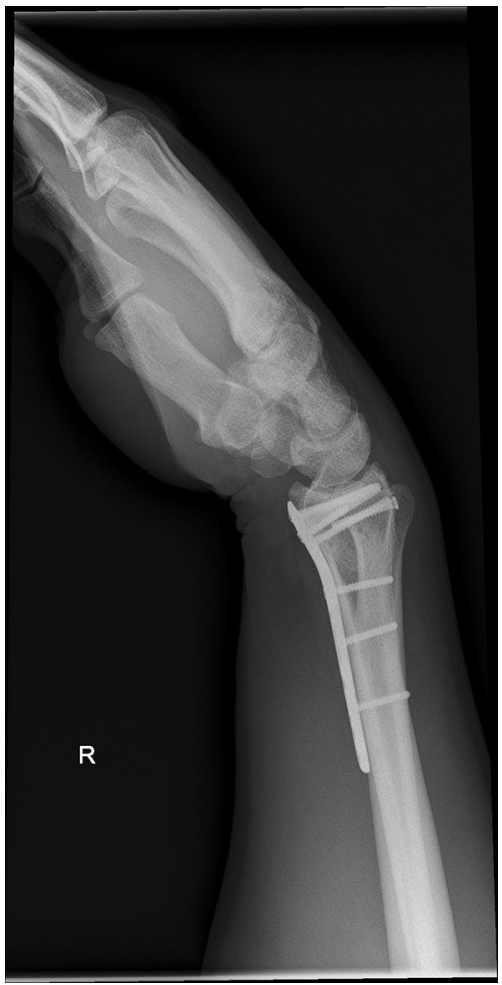

Fig. 25 Lateral view in a flexed and extended position of the wrist before implant removal

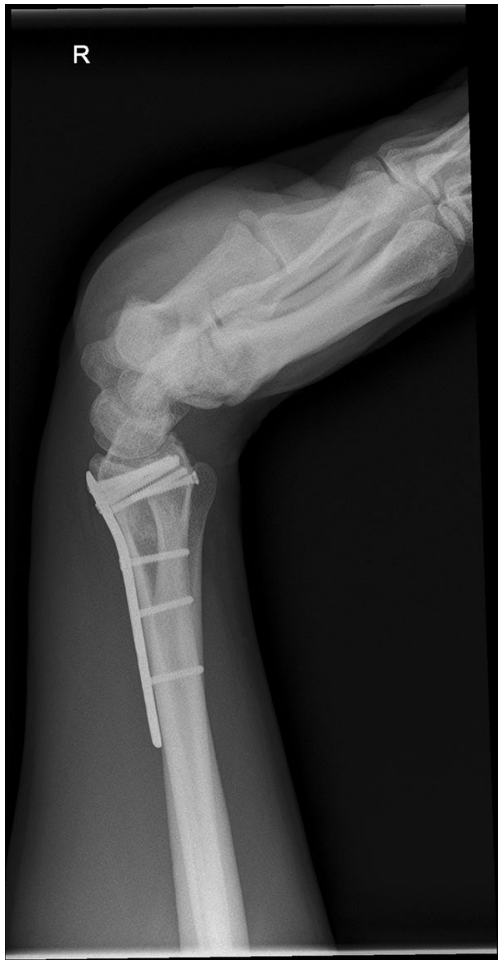

Fig. 26 Lateral view in a flexed and extended position of the wrist before implant removal

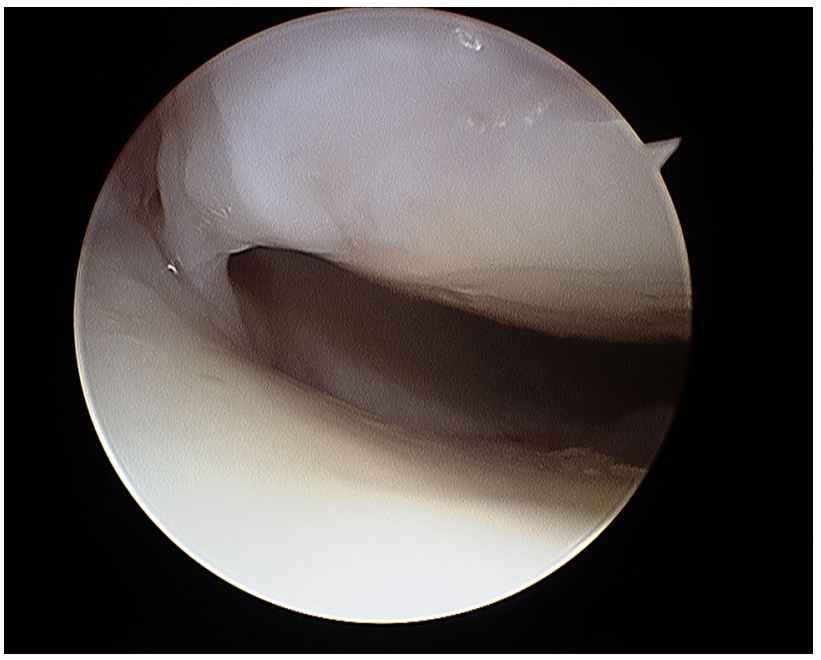

Fig. 27 Arthroscopic view of the palmar side identifying palmar scar formations

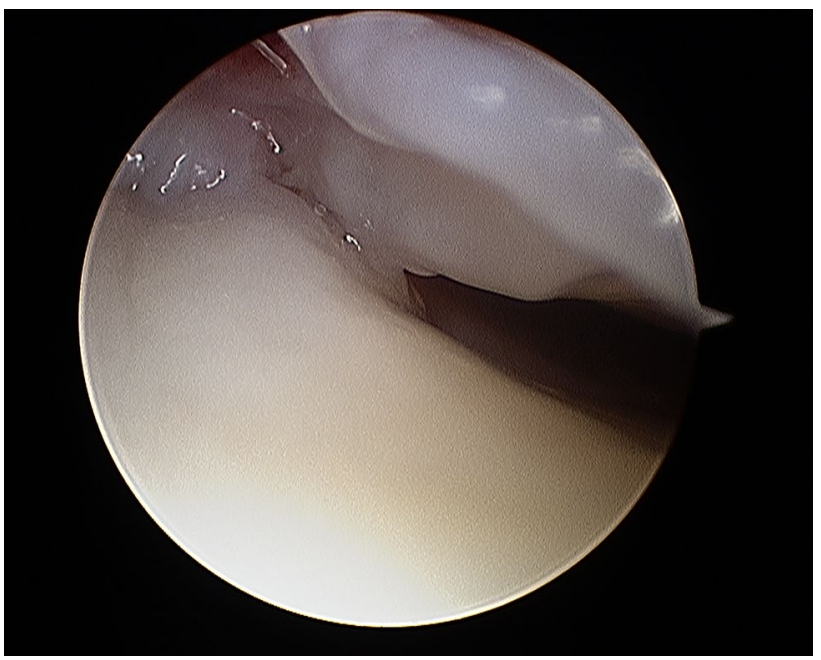

Fig. 28 Arthroscopic view of the palmar side identifying palmar scar formations

Additionally, two palmarly located fragments and a dorso-ulnar fragment were detected in the CT scan performed after initial closed reduction and cast immobilization (Figs. 12, 13, 14 and 15). At the time of surgery, after plate presetting and insertion of the arthroscope through the portal 3/4, the displaced fracture fragments were evaluated (Fig. 16) and debrided (Fig. 17) using a shaver. After arthroscopically assisted fracture reduction, the fragments showed anatomical alignment (Fig. 18). The fluoroscopic images reassured the anatomic reduction in the antero-posterior and lateral view (Figs. 19 and 20). X-ray follow-up at 4 weeks after surgery showed a stable situation without 


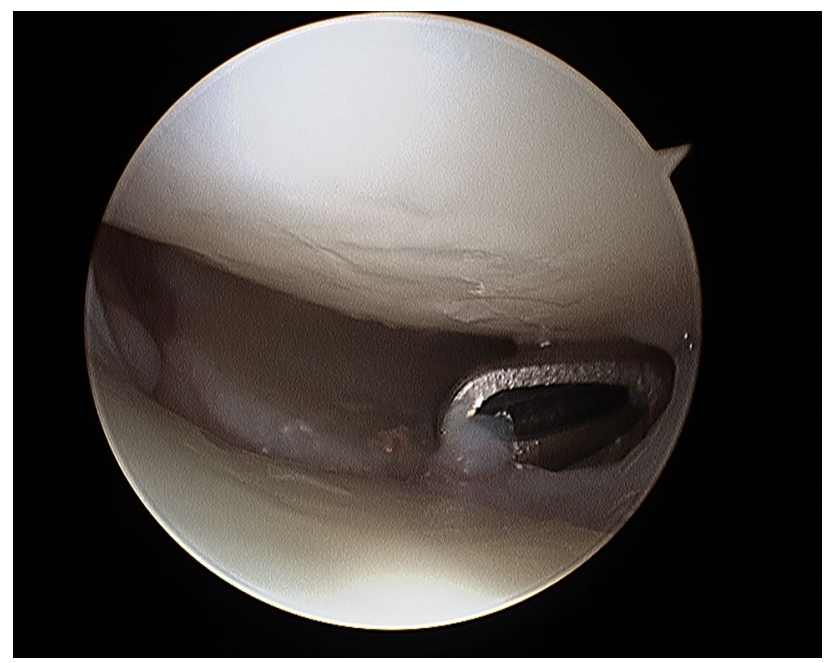

Fig. 29 Arthroscopic view of the dorsal side identifying palmar scar formations

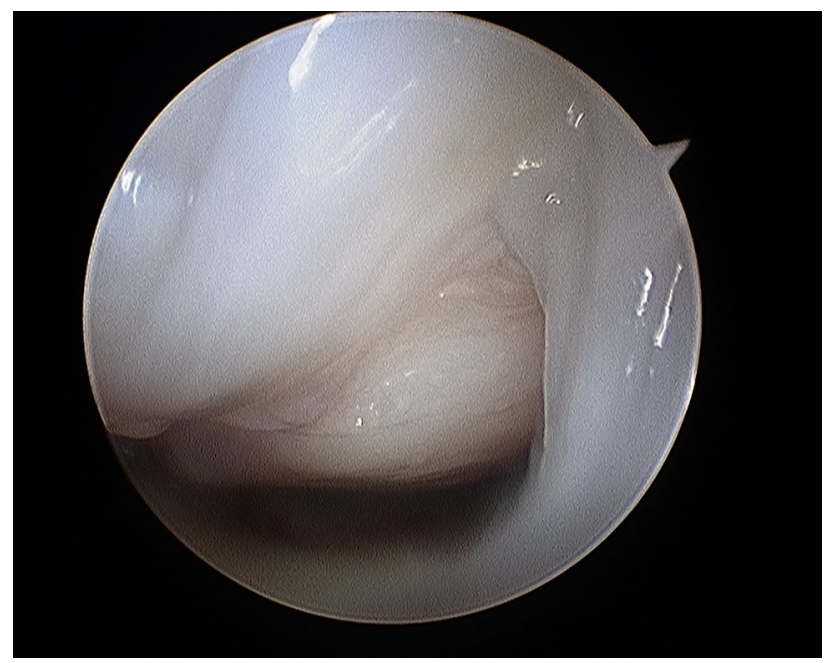

Fig. 30 Arthroscopic view of the dorsal side identifying palmar scar formations

any loss of reduction (Figs. 21 and 22). After 1 year X-rays showed a stable situation (Figs. 23 and 24). Occasional therapy was continuously performed until the range of motion (ROM) was $\mathrm{S}$ (Extension/Flexion) 60/0/40 and R (Rotation) $80 / 0 / 80$ (Figs. 25 and 26). The arthroscopic view at the time of implant removal showed a palmar (Figs. 27 and 28) and dorsal (Figs. 29 and 30) scar formations limiting the ROM.

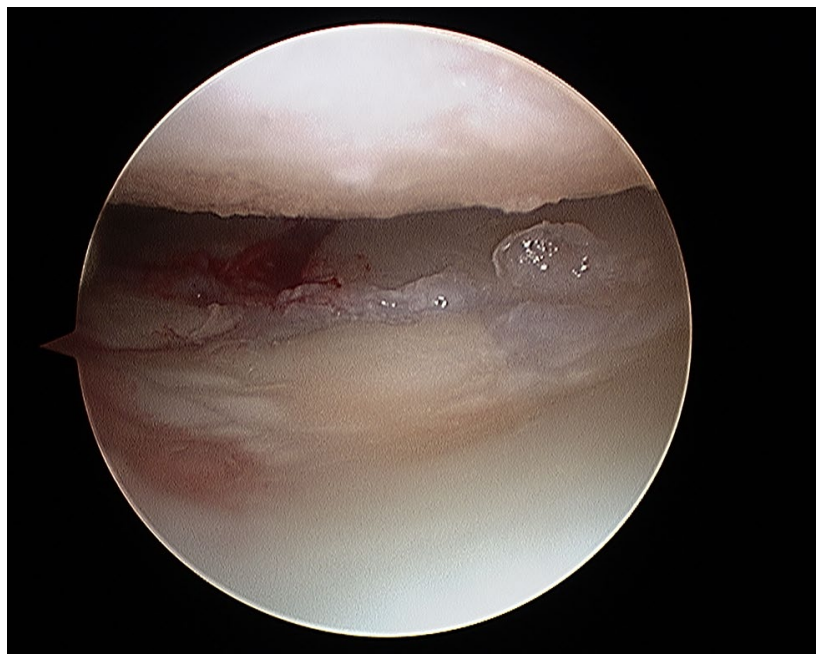

Fig. 31 Arthroscopic view after debridement showing a gap at the volar side

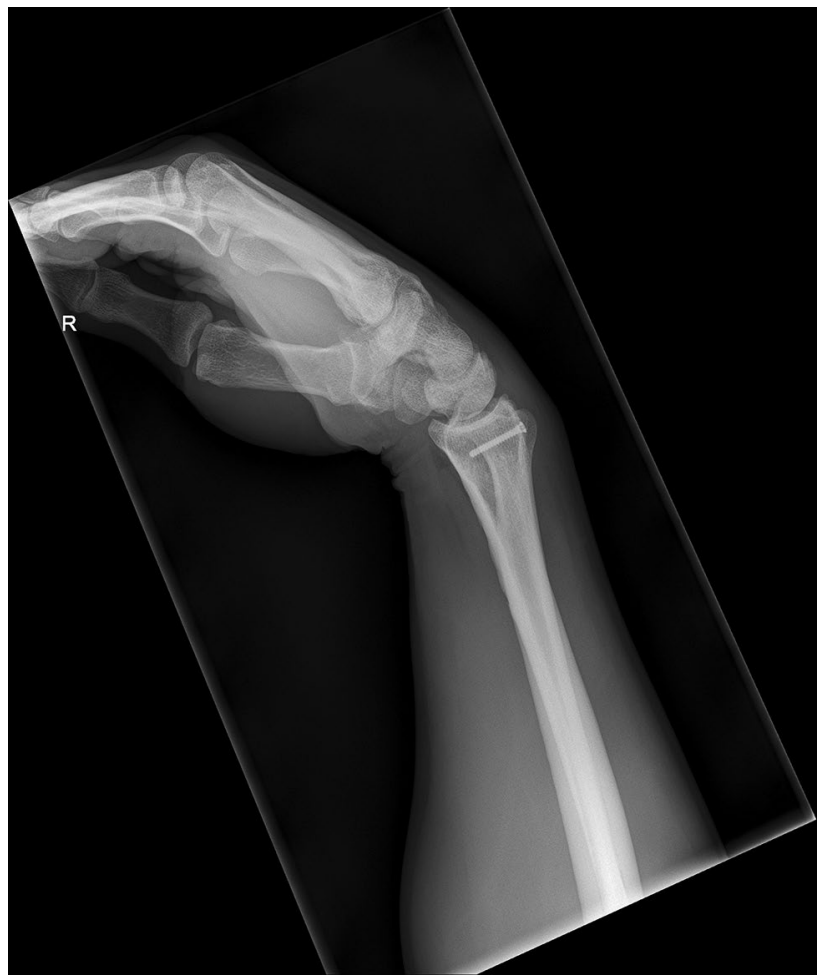

Fig. 32 Lateral view in a flexed and extended position of the wrist after implant removal and arthroscopic debridement showing an improved range of motion 


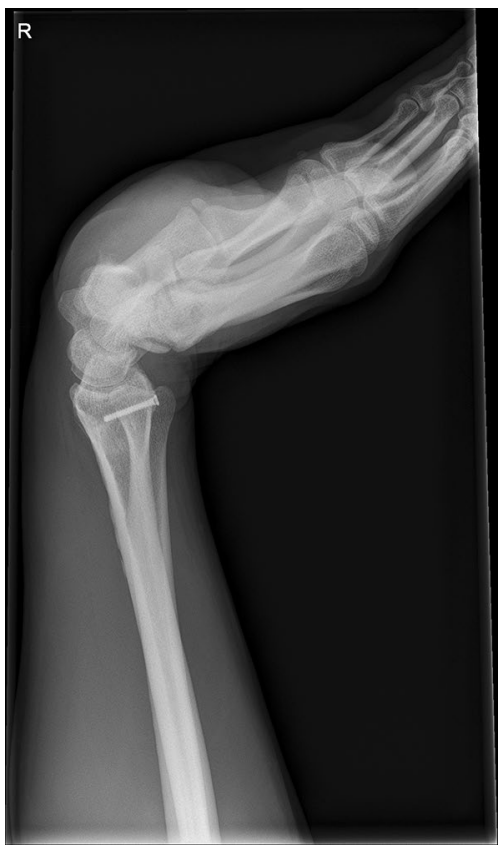

Fig. 33 Lateral view in a flexed and extended position of the wrist after implant removal and arthroscopic debridement showing an improved range of motion

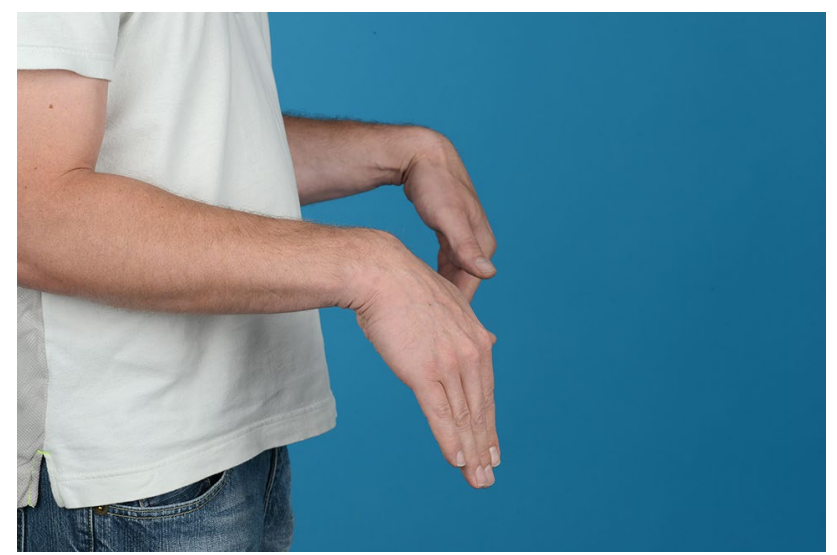

Fig. 34 Clinical photographs in wrist extension and flexion after implant removal

Intra-articular debridement was conducted (Fig. 31). Eight months after implant removal X-rays in extended and flexed wrist position were conducted showing a ROM S (Extension/Flexion) 80/0/80 (Figs. 32 and 33). Clinical results of the patient in an extended und flexed position showing the good ROM (Figs. 34 and 35).

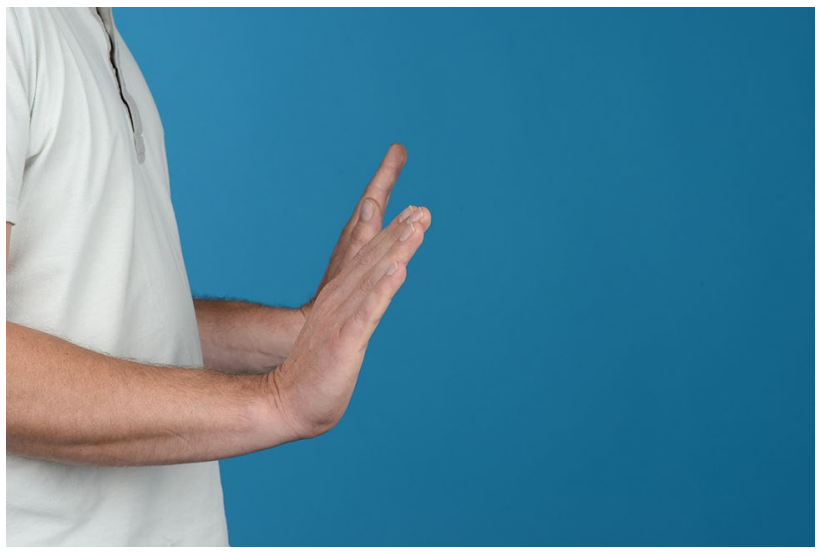

Fig. 35 Clinical photographs in wrist extension and flexion after implant removal

Acknowledgments Open access funding provided by University of Innsbruck and Medical University of Innsbruck. We thank Erin Naismith for proof reading this article.

\section{Compliance with ethical standards}

Conflict of interest No author has a conflict of interest that relates to the content discussed in this manuscript. None of the authors' professional or financial affiliations that may be perceived as having biased the manuscript. Each author certifies that he or she, or a member of their immediate family, has no commercial associations (i.e., consultancies, stock ownership, equity interest, patent/licensing arrangements, etc.) that might pose a conflict of interest in connection with the submitted article.

Open Access This article is licensed under a Creative Commons Attribution 4.0 International License, which permits use, sharing, adaptation, distribution and reproduction in any medium or format, as long as you give appropriate credit to the original author(s) and the source, provide a link to the Creative Commons licence, and indicate if changes were made. The images or other third party material in this article are included in the article's Creative Commons licence, unless indicated otherwise in a credit line to the material. If material is not included in the article's Creative Commons licence and your intended use is not permitted by statutory regulation or exceeds the permitted use, you will need to obtain permission directly from the copyright holder. To view a copy of this licence, visit http://creativecommons.org/licenses/by/4.0/.

\section{References}

1. Koval KJ, Harrast JJ, Anglen JO, Weinstein JN (2008) Fractures of the distal part of the radius. The evolution of practice over time. Where's the evidence? J Bone Jt Surg Am 90(9):1855-1861

2. Atesok K, Doral MN, Whipple T, Mann G, Mei-Dan O, Atay OA et al (2011) Arthroscopy-assisted fracture fixation. Knee Surg Sports Traumatol Arthrosc 19(2):320-329

3. Dei Giudici L, Di Muzio F, Bottegoni C, Chillemi C, Gigante A (2015) The role of arthroscopy in articular fracture management: the lower limb. Eur J Orthop Surg Traumatol 25(5):807-813 
4. Smeraglia F, Del Buono A, Maffulli N (2016) Wrist arthroscopy in the management of articular distal radius fractures. Br Med Bull 119(1): $157-165$

5. Ardouin L, Durand A, Gay A, Leroy M (2018) Why do we use arthroscopy for distal radius fractures? Eur J Orthop Surg Traumatol 28(8):1505-1514

6. Mathoulin C, Sbihi A, Panciera P (2001) Interest in wrist arthroscopy for treatment of articular fractures of the distal radius: report of 27 cases. Chir Main 20(5):342-350

7. Forward DP, Lindau TR, Melsom DS (2007) Intercarpal ligament injuries associated with fractures of the distal part of the radius. $J$ Bone Jt Surg Am 89(11):2334-2340

8. Hohendorff B, Eck M, Muhldorfer M, Fodor S, Schmitt R, Prommersberger KJ (2009) Palmar wrist arthroscopy for evaluation of concomitant carpal lesions in operative treatment of distal intraarticular radius fractures. Handchir Mikrochir Plast Chir 41(5):295-299

9. Fontes D (2016) Pathology of the triangular fibrocartilaginous complex in distal radius fractures. Hand Surg Rehabil 35S:S60-S68

10. Lindau T (2017) Arthroscopic evaluation of associated soft tissue injuries in distal radius fractures. Hand Clin 33(4):651-658

11. Hintringer WRR, Pezzei $C$ et al (2020) Biomechanical considerations on a CT based treatment-oriented classification in radius fractures. Arch Orthop Trauma Surg. https://doi.org/10.1007/ s00402-020-03405-7

12. Chung KC, Spilson SV (2001) The frequency and epidemiology of hand and forearm fractures in the United States. J Hand Surg Am 26(5):908-915

13. Wilcke MK, Hammarberg H, Adolphson PY (2013) Epidemiology and changed surgical treatment methods for fractures of the distal radius: a registry analysis of 42,583 patients in Stockholm County, Sweden, 2004-2010. Acta Orthop 84(3):292-296

14. MacIntyre NJ, Dewan N (2016) Epidemiology of distal radius fractures and factors predicting risk and prognosis. J Hand Ther 29(2):136-145

15. Flinkkila T, Sirnio K, Hippi M, Hartonen S, Ruuhela R, Ohtonen $P$ et al (2011) Epidemiology and seasonal variation of distal radius fractures in Oulu, Finland. Osteoporos Int 22(8):2307-2312

16. Knirk JL, Jupiter JB (1986) Intra-articular fractures of the distal end of the radius in young adults. J Bone Jt Surg Am 68(5):647-659

17. Lameijer CM, Ten Duis HJ, Vroling D, Hartlief MT, El Moumni M, van der Sluis CK (2018) Prevalence of posttraumatic arthritis following distal radius fractures in non-osteoporotic patients and the association with radiological measurements, clinician and patient-reported outcomes. Arch Orthop Trauma Surg 138(12):1699-1712

18. Mayfield JK, Johnson RP, Kilcoyne RF (1976) The ligaments of the human wrist and their functional significance. Anat Rec 186(3):417-428

19. Abe Y, Fujii K (2017) Arthroscopic-assisted reduction of intraarticular distal radius fracture. Hand Clin 33(4):659-668

20. Spies CKGLM, Müller L et al (2020) Distal radioulnar joint instability - current concepts of treatment. Arch Orthop Trauma Surg. https://doi.org/10.1007/s00402-020-03371-0

21. Hagert E, Lalonde DH (2012) Wide-awake wrist arthroscopy and open TFCC repair. J Wrist Surg 1(1):55-60

22. Del Pinal F (2011) Technical tips for (dry) arthroscopic reduction and internal fixation of distal radius fractures. J Hand Surg Am 36(10):1694-1705

23. Leclercq C, Mathoulin C, Members of E (2016) Complications of wrist arthroscopy: a multicenter study based on 10,107 arthroscopies. J Wrist Surg 5(4):320-326

24. Fernandez DL, Geissler WB (1991) Treatment of displaced articular fractures of the radius. J Hand Surg Am 16(3):375-384
25. Trumble TE, Schmitt SR, Vedder NB (1994) Factors affecting functional outcome of displaced intra-articular distal radius fractures. J Hand Surg Am 19(2):325-340

26. Mehta JA, Bain GI, Heptinstall RJ (2000) Anatomical reduction of intra-articular fractures of the distal radius. An arthroscopicallyassisted approach. J Bone Jt Surg Br 82(1):79-86

27. Catalano LW 3rd, Barron OA, Glickel SZ (2004) Assessment of articular displacement of distal radius fractures. Clin Orthop Relat Res 423:79-84

28. del Pinal F, Garcia-Bernal FJ, Pisani D, Regalado J, Ayala H, Studer A (2007) Dry arthroscopy of the wrist: surgical technique. J Hand Surg Am 32(1):119-123

29. Lutz M, Erhart S, Deml C, Klestil T (2016) Arthroscopically assisted osteosynthesis of intraarticular distal radius fractures. Oper Orthop Traumatol 28(4):279-290

30. Pillukat T, Fuhrmann R, Windolf J, van Schoonhoven J (2014) Arthroscopy of the distal radioulnar joint. Oper Orthop Traumatol 26(6):547-555

31. Wegmann K, Harbrecht A, Hackl M, Uschok S, Leschinger T, Muller LP (2019) Inducing life-like distal radius fractures in human cadaveric specimens: a tool for enhanced surgical training. Arch Orthop Trauma Surg. https://doi.org/10.1007/s00402-01903313-5

32. Leixnering MRR, Pezzei $C$ et al (2020) Indications, surgical approach, reduction and stabilization techniques of distal radius fractures. Arch Orthop Trauma Surg. https://doi.org/10.1007/ s00402-020-03365-y

33. Saab M, Guerre E, Chantelot C, Clavert P, Ehlinger M, Bauer T et al (2019) Contribution of arthroscopy to the management of intra-articular distal radius fractures: knowledge update based on a systematic 10-year literature review. Orthop Traumatol Surg Res. https://doi.org/10.1016/j.otsr.2019.06.016

34. Catalano LW 3rd, Cole RJ, Gelberman RH, Evanoff BA, Gilula LA, Borrelli J Jr (1997) Displaced intra-articular fractures of the distal aspect of the radius. Long-term results in young adults after open reduction and internal fixation. J Bone Jt Surg Am 79(9):1290-1302

35. Goldfarb CA, Rudzki JR, Catalano LW, Hughes M, Borrelli J Jr (2006) Fifteen-year outcome of displaced intra-articular fractures of the distal radius. J Hand Surg Am 31(4):633-639

36. Herzberg $G$ (2010) Intra-articular fracture of the distal radius: arthroscopic-assisted reduction. J Hand Surg Am 35(9): 1517-1519

37. Lindau T, Adlercreutz C, Aspenberg P (2003) Cartilage injuries in distal radial fractures. Acta Orthop Scand 74(3):327-331

38. Herzberg G, Merlini L, Burnier M (2017) Hemi-arthroplasty for distal radius fracture in the independent elderly. Orthop Traumatol Surg Res 103(6):915-918

39. Quadlbauer S, Leixnering M, Jurkowitsch J, Hausner T, Pezzei C (2017) Volar radioscapholunate arthrodesis and distal scaphoidectomy after malunited distal radius fractures. J Hand Surg Am 42(9):754 e1-754 e8

40. Burnier M, Le Chatelier RM, Herzberg G (2018) Treatment of intra-articular fracture of distal radius fractures with fluoroscopic only or combined with arthroscopic control: a prospective tomodensitometric comparative study of 40 patients. Orthop Traumatol Surg Res 104(1):89-93

41. Keuchel-Strobl T, Quadlbauer S, Jurkowitsch J, Rosenauer R, Hausner T, Leixnering M, Pezzei Ch (2020) Salvage procedure after malunited distal radius fractures and management of pain and stiffness. Arch Orthop Trauma Surg. https://doi.org/10.1007/ s00402-020-03369-8

42. Gabl M, Arora R, Klauser AS, Schmidle G (2016) Characteristics of secondary arthrofibrosis after intra-articular distal radius fracture. Arch Orthop Trauma Surg 136(8):1181-1188 
43. Selles CA, Mulders MAM, Colaris JW, van Heijl M, Cleffken BI, Schep NWL (2019) Arthroscopic debridement does not enhance surgical treatment of intra-articular distal radius fractures: a randomized controlled trial. J Hand Surg Eur. https://doi. org/10.1177/1753193419866128

44. Geissler WB, Freeland AE, Savoie FH, McIntyre LW, Whipple TL (1996) Intracarpal soft-tissue lesions associated with an intraarticular fracture of the distal end of the radius. J Bone Jt Surg Am 78(3):357-365

45. Lindau T, Arner M, Hagberg L (1997) Intraarticular lesions in distal fractures of the radius in young adults. A descriptive arthroscopic study in 50 patients. J Hand Surg Br 22(5):638-643

46. Yamazaki H, Uchiyama S, Komatsu M, Hashimoto S, Kobayashi Y, Sakurai T et al (2015) Arthroscopic assistance does not improve the functional or radiographic outcome of unstable intra-articular distal radial fractures treated with a volar locking plate: a randomised controlled trial. Bone Jt J 97-B(7):957-962

47. Richards RS, Bennett JD, Roth JH, Milne K Jr (1997) Arthroscopic diagnosis of intra-articular soft tissue injuries associated with distal radial fractures. J Hand Surg Am 22(5):772-776

48. Geissler WB (2013) Arthroscopic management of scapholunate instability. J Wrist Surg 2(2):129-135

49. Mrkonjic A, Lindau T, Geijer M, Tagil M (2015) Arthroscopically diagnosed scapholunate ligament injuries associated with distal radial fractures: a 13- to 15-year follow-up. J Hand Surg Am 40(6): 1077-1082

50. Ono H, Katayama T, Furuta K, Suzuki D, Fujitani R, Akahane M (2012) Distal radial fracture arthroscopic intraarticular gap and step-off measurement after open reduction and internal fixation with a volar locked plate. J Orthop Sci 17(4):443-449
51. Khanchandani P, Badia A (2013) Functional outcome of arthroscopic assisted fixation of distal radius fractures. Indian J Orthop 47(3):288-294

52. Ogawa T, Tanaka T, Yanai T, Kumagai H, Ochiai N (2013) Analysis of soft tissue injuries associated with distal radius fractures. BMC Sports Sci Med Rehabil 5(1):19

53. Kasapinova K, Kamiloski V (2015) Influence of associated lesions of the intrinsic ligaments on distal radius fractures outcome. Arch Orthop Trauma Surg 135(6):831-838

54. Christiaens N, Nedellec G, Guerre E, Guillou J, Demondion X, Fontaine $C$ et al (2017) Contribution of arthroscopy to the treatment of intraarticular fracture of the distal radius: retrospective study of 40 cases. Hand Surg Rehabil 36(4):268-274

55. Swart E, Tang P (2017) The effect of ligament injuries on outcomes of operatively treated distal radius fractures. Am J Orthop (Belle Mead NJ) 46(1):E41-E46

56. Quadlbauer S, Pezzei C, Jurkowitsch J, Rosenauer R, Pichler A, Schattin S et al (2018) Early complications and radiological outcome after distal radius fractures stabilized by volar angular stable locking plate. Arch Orthop Trauma Surg 138(12):1773-1782

57. Rosenauer RPC, Quadlbauer S et al (2020) Complications after operatively treated distal radius fractures. Arch Orthop Trauma Surg. https://doi.org/10.1007/s00402-020-03372-z

Publisher's Note Springer Nature remains neutral with regard to jurisdictional claims in published maps and institutional affiliations. 